CENTRE for ECONOMIC $P$ E R F O R M A N C E

CEP Discussion Paper No 1072

August 2011

\title{
Trading and Enforcing Patent Rights
}

Alberto Galasso, Mark Schankerman and Carlos J. Serrano 


\begin{abstract}
We study how the market for innovation affects enforcement of patent rights. Conventional wisdom associates the gains from trade with comparative advantage in manufacturing or marketing. We show that these gains imply that patent transactions should increase litigation risk. We identify a new source of gains from trade, comparative advantage in patent enforcement, and show that transactions driven by this motive should reduce litigation. Using data on trade and litigation of individually-owned patents in the U.S., we exploit variation in capital gains tax rates as an instrument to identify the causal effect of trade on litigation. We find that taxes strongly affect patent transactions, and that reallocation of patent rights reduces litigation risk, on average. The impact of trade on litigation is heterogeneous, however. Patents with larger potential gains from trade are more likely to change ownership, suggesting that the market for innovation is efficient. We also show that the impact of trade on litigation depends on characteristics of the transactions.
\end{abstract}

Keywords: patents, litigation, market for innovation, capital gains taxation JEL Classifications: K41, H24, O32, O34

This paper was produced as part of the Centre's Productivity and Innovation Programme. The Centre for Economic Performance is financed by the Economic and Social Research Council.

\title{
Acknowledgements
}

We are grateful to Victor Aguirregabiria, Christian Catalini, Nico Lacetera, Matt Mitchell and Dan Trefler for comments on an earlier draft of the paper. We also thank seminar participants at the University of Toronto and the ZEW in Mannheim. Jelena Bozovic and Christina Kim provided excellent research assistance. We are grateful for financial support from the Centre for Economic Policy at the London School of Economics and the Social Sciences and Humanities Research Council of Canada.

Alberto Galasso is an Assistant Professor of Strategic Management at the University of Toronto. Mark Schankerman is a Research Associate at the Centre for Economic Performance and Professor of Economics, London School of Economics. Carlos J. Serrano is an Assistant Professor of Economics at the University of Toronto.

Published by

Centre for Economic Performance

London School of Economics and Political Science

Houghton Street

London WC2A 2AE

All rights reserved. No part of this publication may be reproduced, stored in a retrieval system or transmitted in any form or by any means without the prior permission in writing of the publisher nor be issued to the public or circulated in any form other than that in which it is published.

Requests for permission to reproduce any article or part of the Working Paper should be sent to the editor at the above address.

(C) A. Galasso, M. Schankerman and C. J. Serrano, submitted 2011 


\section{Introduction}

The 'market for innovation' - the licensing and sale of patents - is an important source of R\&D incentives, especially for small firms and individual inventors for whom patents are often their critical asset. Transactions in patent rights are also important for developing efficient market structures in high-technology sectors. This is because they shape the division of labor, and the nature of competition, between small firms (or individuals) who specialize in innovation but lack the capacity for large scale development, production and marketing, and large firms whose comparative advantage lies in the commercialisation of these inventions (Gans and Stern, 2000; Gans, Hsu and Stern, 2002). The key to realizing these social gains is efficient technology transfer.

Despite these private and social benefits, there is growing concern in the academic and policy debates about the potentially deleterious effects of patent transactions on innovation. The issue is that patent transactions can deter innovation if they take place for the primary purpose of extracting rents through patent litigation, and are not associated with technology transfer. ${ }^{1}$ This concern is at the center of a recent report by the U.S. Federal Trade Commission (2011), and similar risks have been emphasized by the U.S. Supreme Court. ${ }^{2}$ There is sharp disagreement among economic and legal scholars about the scope and severity of this problem. For example, Mann (2005) claims that the detrimental effects from patent transactions are minimal, while Lemley and Shapiro (2007), among others, argue that patent transactions constitute a serious threat of ex post hold-up for manufacturing firms, which discourages investment and innovation and requires policy intervention. Despite the importance of the issue, there are no empirical studies of the impact of the market for patents on patent litigation. ${ }^{3}$

\footnotetext{
${ }^{1}$ In a recent analysis of the patent system, Bessen and Meurer (2008) argue that the heart of the problem is that patent rights are typically characterized by fuzzy boundaries (poor 'patent notice'). This increases the risk of infringement and litigation, and undermines the market for innovation.

${ }^{2}$ The FTC report highlights the risk associated with the activity of patent assertion entities (sometimes called patent trolls), which it defines as firms that obtain nearly all of their patents through acquisitions in order to assert them against manufacturing companies. The Supreme Court has raised similar concerns in a recent, prominent case (MercExchange, L.L.C. v. eBay, Inc., 126 S. Ct. 1837, 2006).

${ }^{3}$ This lack of empirical evidence led the House Judiciary Committee, in April 2011, to amend the Patent Reform bill (H.R. 1249, "The America Invents Act") to require the Comptroller General of the United States to study the impact of patent transactions and litigation on innovation.
} 
Understanding this issue is important because higher enforcement costs impose an 'innovation tax' on the incentives the patent system is designed to provide, and there is evidence that small firms are particularly affected by such costs. ${ }^{4}$

In this paper we study how the market for patents affects the enforcement of patent rights. The economics and management literature typically associates the gains from trade in patent transactions with vertical specialization (Teece, 1986; Arora, Fosfuri and Gambardella, 2001) and comparative advantages in manufacturing or marketing (Arora and Ceccagnoli, 2006). By raising the potential profit from the innovations, these mechanisms imply that market reallocation of patent rights should increase the likelihood of litigation. In this paper we identify a novel source of private, and social, gains from trade - comparative advantage in patent enforcement. The market for innovation can reduce litigation if it reallocates patents to entities that are more effective at resolving disputes over these rights without resorting to the courts. ${ }^{5}$ We provide a simple model to illustrate these two conceptually distinct sources of gains from trade and their impact on litigation. A third, more controversial motivation for patent transactions is patent trolling - acquisition of patent rights for later use against existing manufacturing firms. If this is the driving force behind patent transactions, we would expect to observe that a change of ownership raises the likelihood of litigation on the traded patent.

The main focus of this paper is to identify empirically the impact of trade on litigation, and to assess the relative importance of commercialization and enforcement gains from trading patent rights (we briefly explore the patent troll issue later in the paper). To do so, we construct a new, comprehensive data set that matches information on trades (Serrano, 2010) and litigation (Lanjouw and Schankerman 2001, 2004) involving patents owned by individual inventors in the United States during the period 1983-2000.

The empirical challenge in studying how reallocation of patent rights affects litigation is the endogeneity of patent trading. To address this concern, we exploit a provision in the U.S.

\footnotetext{
${ }^{4}$ For example, Lerner (1995) provides evidence of this 'innovation tax' by showing that small biotechnology firms avoid R\&D areas where the threat of litigation is high. Lanjouw and Lerner (2002) show that the risk of preliminary injunctions against infringers can discourage R\&D by small firms.

${ }^{5}$ This may involve acquisition by firms to accumulate defensive patent portfolios for resolving dispute nonlitigously (Hall and Ziedonis, 2001) or some form of economy of scale in enforcement (Lanjouw and Schankerman, 2004). Defensive patenting is particularly prevalent in high technology sectors where there is widespread fragmentation of patent rights over important inputs used in the R\&D and production processes.
} 
tax law that allows us to use variation in capital gains tax rates across states and over time as an instrument to identify the causal effect of a change in patent ownership on litigation. Under U.S. law, for an individual patent-holder the profits from the sale of a patent are taxed as capital gains while any damage awards from litigation are taxed as ordinary income. This means that capital gain tax rates affect the incentives to sell patents for individual owners, but not their incentives to undertake patent litigation, and are thus a suitable instrument for change in ownership in the patent litigation regression. This identification strategy means that we can only study patents that are originally owned by individual inventors in this paper. ${ }^{6}$

The main empirical findings in the paper are as follows. First, we show that capital gains taxation strongly affects the decision to trade patent rights for individual inventors. This finding is consistent with recent literature on how taxation affects the frequency and timing of the sale of small businesses (Chari, Golosov, and Tsyvinski, 2005; Gentry, 2010). We conduct simulations using our parameter estimates that show that changes in capital gains taxation can have large effects on the frequency of patent transactions and litigation.

Second, we find that changes in patent ownership reduce the likelihood of litigation for patents originally owned by individual inventors, on average. This implies that enforcement gains dominate commercialization gains (and the effects of any patent trolling activity) in the market for such patents. However, our third key finding is that the marginal treatment effect of an ownership change is highly heterogeneous. We show that patents with larger potential gains from trading are more likely to experience a change in ownership, which indicates that the market for patent transactions works efficiently (at least in this limited sense). We unbundle the heterogeneous treatment effect of patent transactions on litigation by exploring how specific characteristics of the transaction influence this treatment. Specifically, we show that the impact of trade on litigation depends on the size of the buyer's patent portfolio and the technological fit of the traded patent in that portfolio. Sales by individual inventors to other individuals or small firms are not associated with a decline in the (post-trade) probability of litigation. By contrast, sales to firms with larger patent portfolios significantly reduce litigation risk. This is consistent with the economies of scale in enforcement first documented by Lanjouw and Schankerman

\footnotetext{
${ }^{6}$ In a separate paper, we are developing a different identification strategy to study patent transfers for corporate owned patents.
} 
(2004). ${ }^{7}$ In addition we find that, holding the buyer's portfolio size constant, reallocation of patents increases litigation risk more when the traded patent is a better technological fit in the buyer's existing portfolio. This is what we expect since the potential commercialisation gains from the transfer are likely to be larger in such cases.

Finally, we examine whether this increase in litigation risk is due to patent assertion entities - firms that typically gather patents through acquisitions in order to assert them against manufacturing companies (often referred to as patent trolls). We do not find any evidence that patent trolls play a substantial role in our sample of transactions involving individually-owned patents during the period 1983-2000. Whether this conclusion would apply to corporate patent transactions, or the post-2000 period, is left for future research.

Taken together, our empirical findings indicate that a well-functioning market for innovation is important for allocating patent rights efficiently, and that taxation strongly affects this process. As long as small innovators can appropriate part of the commercialization and enforcement gains generated by these transfers, this market increases their incentives to innovate.

The paper is organized as follows. In Section 2 we present a simple model that highlights the commercialisation and enforcement gains from trade, the impact of trade on litigation, and the role of taxation. Section 3 describes the data. In Section 4 we develop the baseline econometric model for estimating the causal effect of trade on litigation, and present the results. In Section 5 we allow for heterogenous marginal treatment effects, and empirically link them to characteristics of the trade. In Section 6 we quantify the impact of taxes on patent trade and litigation by simulating changes in individual tax rates. Brief concluding remarks close the paper.

\footnotetext{
${ }^{7}$ Lanjouw and Schankerman $(2001,2004)$ show that the litigation risk is systematically related to characteristics of the patent (including measures of value and the technology field) and of the patentholder. In particular, they find economies of scale in patent enforcement - firms with larger patent portfolios are more able to resolve disputes without resorting to the courts.
} 


\section{A Model of Patent Trade and Litigation}

Consider an individual, $A$, owning a patent and a firm, $B$, willing to acquire the patent from the individual. ${ }^{8}$ If the individual does not sell the patent, he obtains product market profits from commercializing (licensing or using) the innovation equal to $\pi^{A}$. If the patent is acquired by the firm, it generates product market profits equal to $\pi^{B}$. For simplicity, we assume that the individual has all the bargaining power and extracts the entire surplus from the transaction (results are similar if there is Nash bargaining).

Both A and B face an infringing action by a third party, firm $C$ with probability $\beta$. If the infringing action takes place, the patent owner chooses whether to litigate or settle the dispute. With litigation the patent owner $i=\{A, B\}$ sustains litigation costs $l_{i}$ to secure product market profits. To settle the dispute, the owner gives up a fraction $\left(1-\theta_{i}\right)$ of the profits to firm $\mathrm{C}$. We also assume that there is a zero mean random (monetary) component in the settlement payoff, $\varepsilon$. In this setup, there will be litigation if

$$
\pi^{i}-l_{i} \geq \theta_{i} \pi^{i}+\varepsilon
$$

which occurs with probability

$$
\operatorname{Pr}\left\{\varepsilon \leq \pi^{i}\left(1-\theta_{i}\right)-l_{i}\right\}
$$

We refer to the vector $e^{i}=\left(l_{i}, \theta_{i}\right)$ as the enforcement vector of owner $i=\{A, B\}$. Litigation takes place with probability $\left.\alpha\left(\pi^{A} ; e^{A}\right)=\beta \operatorname{Pr}\left\{\varepsilon \leq \pi^{A}\left(1-\theta_{A}\right)-l_{A}\right)\right\}$ if the patent is owned by the individual and with probability $\left.\alpha\left(\pi^{B} ; e^{B}\right)=\beta \operatorname{Pr}\left\{\varepsilon \leq \pi^{B}\left(1-\theta_{B}\right)-l_{B}\right)\right\}$ if the patent is owned by the firm. Notice that $\partial \alpha\left(\pi^{i} ; e^{i}\right) / \partial \pi^{i}>0$ whereas $\partial \alpha\left(\pi^{i} ; e^{i}\right) / \partial l_{i}<0$ and $\partial \alpha\left(\pi^{i} ; e^{i}\right) / \partial \theta_{i}<0$.

To start, we consider the case in which there are no taxes. If the individual does not trade the patent, expected profits are

$$
\begin{aligned}
& (1-\beta) \pi^{A}+\alpha\left(\pi^{A} ; e^{A}\right)\left(\pi^{A}-l_{A}\right)+\left(\beta-\alpha\left(\pi^{A} ; e^{A}\right)\right) \theta_{A} \pi^{A} \\
= & \left(1-\Delta_{A}\right) \pi^{A}-\alpha\left(\pi^{A} ; e^{A}\right) l_{A}
\end{aligned}
$$

where the term $\Delta_{A}=\left(\beta-\alpha\left(\pi^{A} ; e^{A}\right)\right)\left(1-\theta_{A}\right)$ captures the expected fraction of profits lost because of settlement between $\mathrm{A}$ and $\mathrm{C}$, and $\alpha\left(\pi^{A} ; e^{A}\right) l_{A}$ captures the expected litigation

\footnotetext{
${ }^{8}$ In this paper we do not model the microfoundations of the search process through which matching occurs.
} 
costs. Similarly, if the patent is owned by firm B, profits are $\left[\left(1-\Delta_{B}\right) \pi^{B}-\alpha\left(\pi^{B} ; e^{B}\right) l_{B}\right]$ where $\Delta_{B}=\left(\beta-\alpha\left(\pi^{B} ; e^{B}\right)\right)\left(1-\theta_{B}\right)$.

The individual will sell the patent if

$$
\left[\left(1-\Delta_{B}\right) \pi^{B}-\alpha\left(\pi^{B} ; e^{B}\right) l_{B}\right] \geq\left[\left(1-\Delta_{A}\right) \pi^{A}-\alpha\left(\pi^{A} ; e^{A}\right) l_{A}\right]
$$

which can be re-written as

$$
\left(\pi^{B}-\pi^{A}\right)+\left(\Delta_{A} \pi^{A}-\Delta_{B} \pi^{B}\right)+\left(\alpha\left(\pi^{A} ; e^{A}\right) l_{A}-\alpha\left(\pi^{B} ; e^{B}\right) l_{B}\right) \geq 0
$$

Condition (2) highlights three possible sources of gains from trade. The first term captures product market gains, i.e. the greater profits that firm $B$ obtains from selling the product. The second and third terms capture the enforcement gains which take the form of losing less profit from settlement, $\Delta_{A} \pi^{A}-\Delta_{B} \pi^{B}$, and incurring lower expected litigation costs, $\alpha\left(\pi^{A} ; e^{A}\right) l_{A}-\alpha\left(\pi^{B} ; e^{B}\right) l_{B}$.

It is straightforward to introduce taxes into the analysis. If the individual owner commercializes the patent, the profits are taxed at the personal income tax rate $\tau^{I}$. If the patent is traded to the firm, the product market profits are taxed at the corporate income tax rate $\tau^{C}$. If the individual owner sells the patent, the gains from the transaction are taxed at the capital gains tax rate $\tau^{G}$. This setup conforms to the U.S. tax code (see Section 4 for more details). With taxes, we get the following conditions for the decision to litigate and to trade the patent, respectively:

$$
\begin{gathered}
\left(\pi^{i}-l_{i}\right)\left(1-\tau^{i}\right) \geq\left(\theta_{i} \pi^{i}+\varepsilon\right)\left(1-\tau^{i}\right) \\
{\left[\left(1-\Delta_{B}\right) \pi^{B}-\alpha\left(\pi^{B} ; e^{B}\right) l_{B}\right]\left(1-\tau^{C}\right)\left(1-\tau^{G}\right) \geq} \\
{\left[\left(1-\Delta_{A}\right) \pi^{A}-\alpha\left(\pi^{A} ; e^{A}\right) l_{A}\right]\left(1-\tau^{I}\right)}
\end{gathered}
$$

where $\tau^{i}=\tau^{I}$ if $i=A$ and $\tau^{i}=\tau^{C}$ if $i=B$.

Note that the capital gains tax rate does not enter the first inequality that governs the litigation decision. ${ }^{9}$ The second inequality, however, shows that the condition required to have

\footnotetext{
${ }^{9}$ Note also that we assume that the probability of litigation $\alpha$ does not depend on the tax rate.
} 
trade becomes more stringent with an increase in $\tau^{G}$, an increase in $\tau^{C}$ or a decrease in $\tau^{I}$. Higher capital gains and corporate taxes reduce the likelihood that patent rights are reallocated, and higher (personal) income tax rates increase it. We test these predictions in the empirical analysis, and exploit the capital gains tax rate as an instrument for trade based on it being excluded from the condition for litigation. ${ }^{10}$

To see how litigation is affected by a change in patent ownership, let $T$ be an indicator variable equal to one if the patent changes ownership and zero otherwise. If individual $A$ does not sell the patent, the probability of litigation is $\operatorname{Pr}($ Litigation $\mid T=0)=\alpha\left(\pi^{A} ; e^{A}\right)$. If trade takes place, the probability is $\operatorname{Pr}($ Litigation $\mid T=1)=\alpha\left(\pi^{B} ; e^{B}\right)$. Thus the impact of trade on litigation is

$$
\operatorname{Pr}(\text { Litigation } \mid T=1)-\operatorname{Pr}(\text { Litigation } \mid T=0)=-\left[\left(\alpha\left(\pi^{A} ; e^{A}\right)-\alpha\left(\pi^{B} ; e^{B}\right)\right] .\right.
$$

This equation shows that the effect of trade on litigation depends on whether it reallocates the patent to an entity with greater product market gains and/or lower enforcement costs. The effect of trade can be either positive or negative, depending on the difference $\alpha\left(\pi^{A} ; e^{A}\right)-$ $\alpha\left(\pi^{B} ; e^{B}\right)$.

Previous literature associates the surplus generated by patent trades with gains from vertical specialization or comparative advantages in manufacturing or marketing. In our model, this commercialisation hypothesis corresponds to the case where $\pi^{A}<\pi^{B}$ and $e^{A}=e^{B}=e$. Because $\partial \alpha\left(\pi^{i} ; e^{i}\right) / \partial \pi^{i}>0$, in this case the change in patent ownership is unambiguously associated with an increase in patent litigation, since $\alpha\left(\pi^{B} ; e\right)-\alpha\left(\pi^{A} ; e\right)>0$. Intuitively, in this scenario trade increases the product market profits generated by the patent but does not alter the enforcement capability of the owner. Because an increase in patent value increases the likelihood of patent litigation (Galasso and Schankerman, 2010), trade increases litigation rates if it is only motivated by product market gains. By contrast, Lanjouw and Schanker-

\footnotetext{
${ }^{10}$ The model assumes that the fee the company pays for the patent is not tax deductible. If we assume that a fraction $g$ of the fee is deductible, the optimal fee becomes

$$
\left[\left(1-\Delta_{B}\right) \pi^{B}-\alpha\left(\pi^{B} ; e^{B}\right) l_{B}\right]\left(1-\tau^{C}\right) /\left(1-g \tau^{C}\right)
$$

which depends (negatively) on corporate taxes as long as $g<1$. Incomplete deductibility is a plausible assumption because, under the current tax code, the cost of acquiring intellectual property must be capitalized (I.R.C. $§ 263)$ and are also subject to a variety of tax depreciation rules (Maine and Nguyen, 2010).
} 
man (2004) document that firms with large patent portfolios are less likely to file a suit on any individual patent in their portfolio (controlling for patent characteristics). This empirical finding corresponds to the case of a trade with a firm with large patent portfolio, such that the difference $\theta_{B}-\theta_{A}$ is positive and large enough to guarantee that $\alpha\left(\pi^{A} ; e^{A}\right)>\alpha\left(\pi^{B} ; e^{B}\right)$. In this case trade is associated with a reduction in the level of patent litigation.

\section{Data}

Our starting point is the panel of patents granted in the period 1975-2000 that are either owned by the original inventor at the grant date or have been assigned to U.S. individuals by the grant date. Hall, Jaffe and Trajtenberg (2001) refer to the first group of patents as 'Unassigned' and to the second group of patents as 'U.S. Individuals' patents. The USPTO refers to both groups as 'Individually Owned' patents. In total these patents represent 17.9 percent of the patents granted in the period 1975-2000. For each of these patents we obtained information on the U.S. state of the primary (first listed) inventor, their reassignment and litigation history. We also collected information on the U.S. state and federal ordinary income taxes, capital gain taxes and corporate taxes during the sample period.

We now describe the main components of our data set.

Patent trade data: We follow Serrano (2010) and use re-assignment data to identify transfers of patents across owners. The source of these data is the USPTO Patent Assignment Database. When a U.S. patent is transferred, an assignment is recorded at the USPTO acknowledging the change in ownership. A typical re-assignment entry indicates the patent involved, the name of the buyer (assignee), the name of the seller (assignor), the date at which the re-assignment was recorded at the patent office, and the date at which the private agreement between the parties was signed. The data set covers the period 1983-2001.

Under Section 261 of the U.S. Patent Act, recording the assignment protects the patent owner against previous unrecorded interests and subsequent assignments. If the patentee does not record the assignment, subsequent recorded assignments will take priority. For these reasons, patent owners have strong incentives to record assignments and patent attorneys strongly recommend this practice (Dykeman and Kopko, 2004). 
A challenge in using re-assignment data is to distinguish changes in patents ownership from other events recorded in the USPTO assignment data. To this end, we use an algorithm developed in Serrano (2010) that conservatively drops all the assignments that appear not to be associated with an actual patent trade. Specifically, we drop assignments in which the buyer is the assignee at the grant date of the patent, and assignments recorded at the patent application date. We also dropped transfers to financial institutions to eliminate transactions (recorded in the USPTO Patent Assignment Database) in which a patent is used as collateral. ${ }^{11}$ Another concern is that the first assignment of an unassigned patent may not correspond to a trade but rather to the transfer of ownership from the inventor to the company in which the inventor works. To deal with this, we drop any transactions where there is evidence that the seller is an inventor working for the buyer. ${ }^{12}$

Litigation data: The patent litigation data set was compiled by Lanjouw and Schankerman $(2001,2004)$. This data set matches litigated patents identified from the Lit-Alert database with information on the progress or resolution of suits from the court database organized by the Federal Judicial Center. The data set contains 14,169 patent cases filed during the period 1975-2000. For each of these case filings, the data set reports detailed information on the main patent litigated, the patentee, the infringer and the court dealing with the case. The data set contains information on patent cases filed in U.S. federal district courts (and not on appeal). For each patent in our data, we identify the suits in which the patent was involved and the year in which the case was filed. ${ }^{13}$

Tax data: Information on state and federal income and capital gain taxes are obtained

\footnotetext{
${ }^{11}$ We also dropped records in which the buyer and seller are the same entity and in which the execution date is either before the application date or after patent expiration. For additional details on the procedure, see Serrano (2010).

${ }^{12}$ Specifically, for each transfer between a seller $i$ and buyer $j$,we identified all the patents which list the seller $i$ as the (primary) inventor and checked whether any of these patents was assigned to the buyer $j$ at its grant date. We drop all such transactions.

${ }^{13}$ The use of re-assignment data as a proxy for activity in the market for innovation can be problematic because technology can be transferred through patent licensing without changes in ownership. This concern is less relevant in our study that focuses on patent litigation because typically it is the owner of the patent that has the right to bring patent infringement actions. Non-exclusive licensees do not have the right to sue for patent infringement (Textile Prods. v. Mead Corp., 134 F.3d 1481, 1485 Fed. Cir. 1998), though an exclusive licensee may have standing to bring such a suit (Prima Tek II, L.L.C. v. A-Roo Co., 222 F.3d 1372, 1377 Fed. Cir. 2000).
} 
from the NBER Tax Rates data base. This contains marginal income tax rates by year and state for a representative household with $\$ 500,000$ of wage income. ${ }^{14}$ The data set also reports maximum federal and state long-term capital gains tax rate by year and state, computed using the NBER TAXIM model. We obtain information on the maximum federal and state corporate marginal tax rates, for each year and state, from two government publications: the Significant Features of Fiscal Federalism (available for the period 1982-1995) (ACIR, 1982-1995) and the Book of the States (for the period 1996-2000) (CSG, 1996-2000). For each assigned patent in our data set, we use the ordinary income and capital gains marginal tax rates in the state of the initial patent assignee. For unassigned patents, we used the state of the primary inventor as identified by the USPTO. To measure tax rates faced by potential corporate buyers, we construct a weighted average of state corporate taxes where state weights are determined by the fraction of state patent applications in the technology class of the patent. ${ }^{15}$

Matching data on income and capital gain taxes to patents is meaningful as long as the patent is owned by an individual at the time of the transaction. To ensure this, we focus our analysis on the first transfer of a patent. Subsequent owners are generally not individuals and thus are not subject to either personal income or capital gains taxation on the patent transaction. Focusing on the first transfer involves dropping very few patent trades. Most of the traded patents in our data are traded only once (94.9 percent) and only 0.15 percent of traded patents are traded more than three times.

The final data set is a panel with 299,356 patents and 2,436,649 patent-age observations. The main variables used in the empirical analysis are described below.

Litigation Dummy ${ }_{i t}$ : dummy variable equal to 1 if at least one suit is filed in a federal court involving patent $i$ at age $t$.

NewOwner ${ }_{i t}$ : dummy variable equal to 1 for patent-ages in which the patent is no longer owned by the original individual assignee/inventor.

Income Tax Rate $_{i t}$ : for each patent-age, the sum of the federal income tax rate and

\footnotetext{
${ }^{14}$ For details, see the description of the TAXSIM program in Feenberg and Coutts (1993). The simulation and the resulting data are available at http://www.nber.org/ taxsim/state-rates/

${ }^{15}$ All our results are robust to the alternative of simply using corporate tax rates in the state of the inventor, which assumes that trading of patents occurs only within states.
} 
the state income tax rate for the state of the primary (first listed) inventor of the patent.

Capital Gains Tax Rate $_{i t}$ : for each patent-age, the sum of the federal capital gain tax rate and the state capital gain tax rate for the state of the primary (first listed) inventor of the patent.

Corporate Tax Rate $_{i t}$ : for each patent-age, the sum of the federal corporate tax rate and a weighted average of the state corporate tax rates. State weights are equal to the fractions of state patent applications in the technology class (USPTO nclass) of the patent in the year of the trade.

Table 1 reports summary statistics for the key variables. Panel A shows the fraction of sample patents involved in trade or litigation at least once in their life. Of the total sample, 4.55 percent of patents are traded and 0.69 percent are involved in at least one suit. These rates are low but it is worth noting that, for the later patents in the sample, data on trade and litigation are truncated and this biases downward litigation and trade rates. ${ }^{16}$ Moreover, patents that are traded or litigated are much more valuable than the those that are not (as measured by citations received). ${ }^{17}$ The striking fact from this table is the strong association between trading and litigation. Of patents that are traded, 4.2 percent are also litigated; for patents that are not traded, the litigation rate is only 0.51 percent. Of patents that are litigated, 27.9 percent are also traded; for patents that are not litigated, only 4.4 percent are traded.

The second panel of Table 1 illustrates the combined (state plus federal) individual and corporate tax rates averaged across states for four five-year time periods. There is a substantial decline in income tax rates in the late eighties and an increase in the early nineties. Conversely, there is an increase in capital gain tax rates in the late eighties and a decrease in the late nineties. The summary statistics show the range of variation across U.S. states. The difference between the lowest and the highest capital gains tax rates across states ranges from 7-9 percentage points (depending on the year). The difference between the minimum and the maximum income tax rate across states is 6 - 16 percentage points. Corporate tax rates decline during the sample

\footnotetext{
${ }^{16}$ For patents where we have litigation and trade data during the first ten years of life (i.e. patents granted in 1983-1991), we find that 11.8 percent are traded and 2.2 percent are litigated.

${ }^{17}$ The mean number of citations for patents that are neither traded nor litigated is 6.1 . The mean is 10.8 for traded patents and 16.5 for litigated patents. For those that are both traded and litigated, the average is 19.3.
} 
period and the difference between the lowest and highest rates is $12-15$ percentage points. ${ }^{18}$ Analysis of variance shows that 89.4 percent of the overall variance in capital gains tax rates is variation over time and 8.7 percent is variation across states (the small remainder is residual). The breakdown for ordinary income tax rates is 92.9 and 6.8 percent; for corporate tax rates, 49.1 and 48.6 percent.

Panel A in Table 1 shows that trade and litigation are associated, but it does not reveal how litigation rates differ before and after a trade occurs. To show this, we focus on patents that are eventually traded (in our sample period). In Figure 1 we compare the probability of being involved in at least one suit prior to and after the date at which trade occurs. In aggregate, a patent that has not been traded but that will be traded in its lifetime is involved in at least one suit in that year with probability 0.61 percent. A patent that has already changed ownership is involved in at least one suit with probability 0.48 percent. The post-trade litigation probability is lower after trade even after we condition on age. For example, a patent that has not yet been traded at age 7 is involved in at least one dispute with probability 0.76 percent, whereas for a patent of the same age that has been already traded, the litigation rate is about that level (0.43 percent). In short, Figure 1 suggests that the reallocation of patent rights is temporally related to lower litigation risk. In the econometric analysis we exploit capital gains tax rates as an instrument to pin down the causal relationship.

In principle, exploiting the information contained in the USPTO assignment data it is possible to recover the patenting activity of the buyers in our sample. Unfortunately, the names of the buyer and seller in the Patent Assignment Database were never standardized by the USPTO. Therefore, to back out buyer patent portfolios we need to match each buyer name manually with a unique assignee identifier required to identify the buyer's patents. Because of the large size of our sample $(17,605$ traded patents), we manually matched only patents that were both traded and litigated at least once in their lifetime (569 patents). In the empirical analysis below, we will present the main regression results both for the entire data set $(299,356$ patents) and for the smaller data set of traded and litigated patents, where we are able to investigate the role of buyer characteristics on the impact of trade.

\footnotetext{
${ }^{18}$ Similar figures are observed if we restrict the analysis to the 20 states with the most individually-owned patents.
} 


\section{Estimating the Effect of Trade on Litigation}

\subsection{Baseline Econometric Model}

Let $L_{i t}$ denote an indicator variable that is equal to 1 if at age $t$ (period $\tau$ ) at least one patent case is filed involving patent $i$. We assume that patents are litigated according to the following linear probability model:

$$
L_{i t}=\beta X_{o t}+\mu_{i}+\lambda_{\tau}+a_{t}+u_{i t}
$$

where $X_{o t}$ are the characteristics of the owner at age $t$ and $u_{i t}$ is the residual component. The terms $\mu_{i}, \lambda_{\tau}$ and $a_{t}$ capture patent fixed effects, period effects and age effects. ${ }^{19}$

Letting $j$ denote the initial owner of the patent and $k$ the buyer of the patent, we can write

$$
X_{o t}=\left(1-T_{i t}\right) X_{j}+T_{i t} X_{k}
$$

where $T_{i t}$ is a dummy that equals one from the date the patent changes ownership, and $X_{j}$ and $X_{k}$ are owners characteristics that we assume are constant over time for simplicity. Then the litigation model can be expressed as

$$
L_{i t}=\beta X_{j}+T_{i t} \beta\left(X_{k}-X_{j}\right)+\mu_{i}+\lambda_{\tau}+a_{t}+u_{i t}
$$

Equation (6) provides useful guidance in interpreting our empirical results. In the next section we will regress litigation on trade in panel regressions of the form

$$
L_{i t}=\alpha T_{i t}+\theta_{i}+\lambda_{\tau}+a_{t}+u_{i t}
$$

In light of equation (6), the patent fixed effects, $\theta_{i}$, will capture the combined effect of the characteristics of the initial owner, $\beta X_{j}$, and the patent characteristics, $\mu_{i}$ (i.e., $\theta_{i}=\beta X_{j}+\mu_{i}$ ). More importantly, the coefficient on the traded dummy, $\alpha$, can be rewritten as $\beta\left(X_{k}-X_{j}\right)$. This has two implications. First, we can interpret the coefficient on trade as the impact that the change in ownership characteristics (if unobservable to the econometrician) has on patent litigation. If we were able to control for all the owner characteristics that affect litigation risk, the coefficient $\alpha$ should be zero. The second implication is that $\alpha$ will differ from zero only

\footnotetext{
${ }^{19}$ We cannot include year dummies because the patent grant year is absorbed by the patent fixed effect. We include dummies for four time periods: before 1986, 1986-90, 1991-95, and after 1995.
} 
if two conditions hold: first, there are unobservable owner characteristics that affect litigation outcomes (i.e., $\beta \neq 0$ ) and, secondly, the market for innovation reallocates patents to entities that differ substantially in these characteristics (i.e., $X_{k} \neq X_{j}$ ). Previous literature on patent litigation confirms that owner characteristics substantially affect litigation risk (e.g., Lanjouw and Schankerman, 2004), but there is no existing research on the link between the reallocation of patent rights and litigation risk. To our knowledge, this is the first paper that studies this link and the sorting which the market for innovation induces. ${ }^{20}$

\section{Identifying the Causal Effect of Trade on Litigation}

To identify the causal effect of trade on litigation, we need to address the potential bias arising from correlation between $T_{i t}$ and $u_{i t}$. This can arise in a variety of ways. A positive shock in the value of the technology covered by the patent may lead to an increase both in the likelihood of trade and litigation. Alternatively, a cash constrained innovator may be more likely to sell its patent and less likely to enforce it aggressively. Another possibility is that litigation may increase because firms acquire patents strategically with the purpose of blocking competitors through patent litigation.

To address potential endogeneity, we need an instrument that affects the likelihood of trading a patent but does not belong directly in the litigation equation. We exploit a feature of the U.S. tax code that allows us to use the capital gain tax rates as an instrument. In the United States Internal Revenue Code, individuals face a lower tax rate on capital gains (from sales of assets) than on ordinary ('earned') income. U.S. corporations do not receive this preferential tax rate on capital gains (Desai and Gentry, 2004). According to section 1235 of the Internal Revenue Code, the transfer of a patent by an individual is treated as the sale of a capital asset and is subject to capital gain taxes. On the other hand, patent litigation damages (and licensing royalties) are taxed as ordinary income. This treatment of litigation damages is

\footnotetext{
${ }^{20}$ It is easy to extend the model to introduce observable characteristics of the owner. Consider the model $L_{i t}=\beta X_{o t}+\gamma \widetilde{X}_{o t}+\mu_{i}+\lambda_{\tau}+a_{t}+u_{i t}$ where $X_{o t}$ are the unobservable characteristics of the owner at age $t$ and $\widetilde{X}_{o t}$ are the observable characteristics of the owner. Because $\widetilde{X}_{o t}$ are observed, we can estimate $L_{i t}=\alpha T_{i t}+\theta_{i}+\gamma \widetilde{X}_{o t}+\lambda_{\tau}+a_{t}+u_{i t}$. In this extended model, the patent fixed effects, $\theta_{i}$ still captures the combined effect of the time invariant unobservable characteristics of the initial owner, $\beta X_{j}$, and the time invariant patent characteristics, $\mu_{i}$ (i.e., $\theta_{i}=\beta X_{j}+\mu_{i}$ ). The coefficient on the traded dummy, $\alpha$, can be still be rewritten as $\beta\left(X_{k}-X_{j}\right)$ and measures the impact that the change in unobservable ownership characteristics has on patent litigation. This extension also implies that if the econometrician is able to observe all the patent characteristics that have an impact on litigation (i. e. $X_{o t}$ is empty) then $\alpha$ would be equal to zero.
} 
acknowledged in a number of tax court decisions (Maine and Nguyen, 2003). This means that the decision to trade a patent will be affected by the capital gains tax rate, but the decision to litigate will not. We limit the analysis in this paper to trades of individually-owned patents because this tax distinction does not apply to patent sales by corporations, so we cannot use this instrumental variable for transfers of company-owned patents.

We start by specifying a probit equation that determines how taxes affect the probability that a patent is traded by the original assignee at age $t$. To do this, we generate a dummy variable, Tradeit, that equals one only in the year in which the patent changes ownership. We drop all the observations that follow the first change in ownership and estimate the following probit regression

$$
\text { Trade }_{i t}=\left\{\begin{array}{lll}
0 & \text { if } & p\left(Z_{i t}, X_{i t}\right) \leq \varepsilon_{i t} \\
1 & \text { if } & p\left(Z_{i t}, X_{i t}\right)>\varepsilon_{i t}
\end{array}\right.
$$

where $Z_{i t}$ is the capital gains tax rate for individuals in the state of the inventor and $X_{i t}$ is a vector of patent characteristics and additional controls. Given the probability of being traded at age $t, p_{i t}$, we can compute the probability that the patent is not owned by the initial owner at age $t$ as

$$
P_{i t}=P_{i t-1}+\left(1-P_{i t-1}\right) p_{i t}
$$

with $P_{i 1}=p_{i 1}$. Intuitively, the probability of not being owned by the original inventor at age $t$ is equal to the probability of having changed ownership in the previous periods plus the probability of not having changed ownership up to age $t$ and being traded at age $t$.

Denote the predicted probability from the probit model (8) as $\widehat{p}_{i t}$. We use $\widehat{p}_{i t}$ to obtain an estimate of the probability of not having changed ownership up to age $t, \widehat{P}_{i t}$. This estimate satisfies two important properties. First, $\widehat{P}_{i t}$ depends on capital gain tax rates $Z_{i t}$ that are assumed to be uncorrelated with the likelihood of patent litigation (except through changes in ownership). Specifically, we expect larger capital gain tax rates to reduce the probability of a change in ownership. ${ }^{21}$ Second, $\widehat{P}_{i t}$ is equal to $E\left(T_{i t} \mid Z_{i t}\right)$. These properties allow us to exploit $\widehat{P}_{i t}$ as an instrumental variable to estimate the effect of trade on litigation (Angrist, 2001).

We define $T\left(Z_{i t}\right)$ as a random variable equal to zero if patent $i$ would not have changed

\footnotetext{
${ }^{21}$ Because $\widehat{P}_{i t}$ is a non-linear function of $\widehat{p}_{i t}, \widehat{p}_{i t-1}, \ldots, \widehat{p}_{i 1}$, it depends on the entire vector of current and past capital gain taxation rates $\bar{Z}_{i t}=\left(Z_{i 1}, Z_{i 2}, \ldots, Z_{i t}\right)$. Nonetheless, the relevant thing in our setting is that, conditional on a patent not having been traded, a change in ownership only depends on $Z_{i t}$.
} 
ownership if it had the instrument equal to $Z_{i t}$, and equal to one if that patent would be traded at $Z_{i t}$. We observe $\left(Z_{i t}, T_{i t}, L_{i t}\right)$ for a random set of patents, where $T_{i t}=T\left(Z_{i t}\right)$ is the trade indicator associated with $Z_{i t}$, and $L_{i t}=L\left(T_{i t}\right)$ is the response variable given the trade status $T_{i t}$. Using this notation, the econometric model can be summarized by

$$
\begin{aligned}
L\left(T\left(Z_{i t}\right)\right. & =1)=\alpha+\theta_{i}+\lambda_{\tau}+a_{t}+u_{i t} \\
L\left(T\left(Z_{i t}\right)\right. & =0)=\theta_{i}+\lambda_{\tau}+a_{t}+u_{i t} \\
T\left(Z_{i t}\right) & =\left\{\begin{array}{lll}
0 & \text { if } & P\left(Z_{i t}\right)<v_{i t} \\
1 & \text { otherwise }
\end{array} \text { and } T_{i t-1}=0\right.
\end{aligned}
$$

where $\alpha$ is the effect of trade on litigation identified using the instrument $Z$. ${ }^{22},{ }^{23}$

\subsection{Empirical Results}

\section{Trade and Litigation: Correlations}

In Table 2, we begin by presenting OLS estimates of our baseline econometric model (7). The first three columns present estimates using the full sample (including patents that are not traded and/or litigated). In column 1, where we do not include any controls, the coefficient on the NewOwner dummy is positive and significant. However, this result is likely due to selection into trading, since more valuable patents are both more likely to be traded and litigated. In column 2 we include patent fixed effects in the specification to control for this possibility. This specification makes use only of within-patent litigation variation. Once fixed effects are included, the coefficient becomes negative and significant, indicating that a patent is less likely to be involved in a suit after it changes ownership. A Hausman test strongly rejects the null hypothesis that the patent effects are random. ${ }^{24}$ The negative correlation between change of

\footnotetext{
${ }^{22}$ We assume that the disturbance in the litigation equation, $u_{i t}$, does not depend on whether the patent is traded. It is easy to generalise to allow for different disturbances.

${ }^{23}$ Notice that, conditioning on a patent not having changed ownership $\left(T_{i t-1}=0\right)$, trade occurs if $p\left(Z_{i t}\right)>\varepsilon_{i t}$. Multiplying both sides of the inequality by $\left(1-P_{i t-1}\right)$ and adding $P_{i t-1}$, we obtain

$$
P_{i t}>v_{i t} \equiv P_{i t-1}+\left(1-P_{i t-1}\right) \varepsilon_{i t}
$$

This is the relationship between $T$ and $P$ described in the third formula of the econometric model. Even if the $\varepsilon_{i t}$ are assumed to be independent draws, the impact of $v_{i t}$ on $T$ depends on the entire sequence of past realizations of $\varepsilon_{i t}$. The serial correlation in $v_{i t}$ is not a problem as long as $v_{i t}$ is uncorrelated with $Z_{i t}$.

${ }^{24}$ To perform the test, we run a random effect panel regression with additional covariates. The additional controls are the number of citations made by the patent, the number of citations received, the number of claims, and the technology class of the patent. The random effect coefficient on NewOwner is positive and significant
} 
ownership and litigation is robust when we introduce age effects and time period dummies, in column $3 .^{25}$ Finally, in column 4 we present a similar regression using the much smaller subsample of patents that are both traded and litigated at least once in their life. Also in this smaller sample we find a negative correlation between trading and litigation, but not statistically significant. ${ }^{26}$

The results in Table 2 are to be interpreted as correlations between litigation rates and changes in ownership, not causal impacts. As we argued above, there are a number of reasons why we should expect unobservable factors to affect both the trading and litigation decisions. This intuition is confirmed by a Rivers-Vuong test that provides strong evidence against the exogeneity of patent trade. ${ }^{27}$ To address this endogeneity we will now construct an instrument that relies on the effect of capital gains taxes on patent trading.

\section{Impact of Taxes on Patent Trading}

Table 3 presents estimates of the impact of taxes on changes in patent ownership. The dependent variable is an indicator variable, Trade, that equals one only in the year in which the patent changes ownership. Because tax rates affect the initial owner incentives to sell the patent up to the time at which the patent is sold, we estimate these regressions dropping all observations that follow the first change in ownership. In all the regressions we control for a range of observable patent characteristics, including the number of citations received by the patent, a measure of the patent generality, technology class (36 two-digit sub-categories), plus

in the random effect specification $(\hat{\beta}=0.003, p-$ value $<0.01)$. The estimate from the fixed effect specification is negative and significant $(\hat{\beta}=-0.002, p-$ value $<0.01)$. We strongly reject that the two estimates are equal $\left(\chi_{20}^{2}=1878.19, p-\right.$ value $\left.<0.01\right)$.

\footnotetext{
${ }^{25}$ In this regression we add dummies for four sub-periods: before 1986, 1986-90, 1991-95, and after 1995 . In a more general specification with a dummy for each year and no age dummies, we do not reject the joint hypothesis that the individual year coefficients can be summarised by these four period dummies.

${ }^{26}$ We observe a similar negative correlation even when we drop the unassigned patents and focus on patents that are assigned to a US individual at their grant date (14,576 patents). The correlation between trade and litigation is negative and significant at the 5 percent level. The confidence interval of the coefficient on traded overlaps with the one estimated in the large sample.

${ }^{27}$ Following Rivers and Vuong (1998), we regressed NewOwner on capital gain taxes, age dummies and period dummies in a linear probability model with fixed patent effects. We constructed the residuals $(\hat{v})$ for this model and then regressed the litigated dummy on NewOwner, age, period dummies and $\hat{v}$. The coefficient on $\hat{v}$ is positive and highly significant (point estimate of $0.054, p-$ value $<0.01$ ).
} 
year and age fixed effects. ${ }^{28}$

Column 1 presents the estimates of the probit model (8). Consistent with Serrano (2010), we find that more valuable and general patents are more likely to be traded. The important, new results involve the impact of taxes. The regression confirm that higher capital gains and corporate tax rates reduce the likelihood that patent rights are traded, and higher income tax rates increase it. These results are consistent with the predictions of the model presented in Section 2. Moreover, the estimated marginal effects from column 1 imply large tax impacts. The elasticity of the probability of trade with respect to the capital gains tax rate is -1.62 . The corresponding elasticities for the personal income tax rate and corporate tax rate are 1.22 and -0.77 , respectively. In column 2 we show that results are similar if we use a linear probability model. $^{29}$

In column 3 we focus on the sub-sample of patents that are litigated and traded at least once in their lifetime. Despite the huge reduction in sample size, we still find a negative and significant coefficient for capital gains tax rates. In this restricted sample the estimated coefficients on citations received and generality are not significant. This is not surprising because all the patents in this smaller sample are traded, and our time-invariant measures of patent characteristics have little explanatory power on the timing of trade.

There is a concern that the impact of taxes on trade may reflect omitted variables correlated with tax rates rather than incentives to trade generated by the asymmetric tax treatment of trade and litigation faced by individuals. To check this possibility, in column 4 we conduct a placebo test by running a similar probit regression using the sample of patents that are assigned to U.S. corporations by the time they are granted. Because firms pay corporate taxes both on profits from selling a patent and on litigation damages, we do not expect taxes

\footnotetext{
${ }^{28}$ We use the NBER data set for information on the number of citations received, grant date and technology class for each patent. Since citation counts are inherently truncated, we use the truncation adjusted citations counts contained in the NBER patent data (see Hall et. al., 2001, for details). The NBER data also provides an index of patent "generality". This measure equals to one minus the Herfindahl index of the citations received by a patent across different technology classes. The measure is high if the patent is cited by a wide range of technology fields.

${ }^{29}$ In the specification reported in the table we do not include patent fixed effects because we want to be able to exploit cross-state variation in tax rates. However, the results are robust to introducing patent fixed effects in the linear probability model, where we obtain a coefficient of $-0.118(p-$ value $=0.01)$ and a 95 percent confidence interval that includes the point estimate in column 2. The marginal effect for capital gain taxes is also similar if we estimate using a logit specification, even with a correction for rare events.
} 
to affect corporate patent trade decisions. This placebo test confirms that taxes have no effect on the likelihood of trade for company-owned patents. We also find that more 'general' patents are more likely to be traded (as with individual owned patents). In line with Serrano (2010), the results show that large firms (those with more than five patents granted in the year of the traded patent) are less likely to trade their valuable patents (measured by citations), which they can presumably exploit themselves. By contrast, small innovators are more likely to trade such patents, suggesting that the potential gains from trade are greater for small patenting entities. ${ }^{30}$

This evidence strongly supports the hypothesis that capital gains, ordinary income and corporate tax rates affect the likelihood that individual patent rights are traded. Since market based reallocations presumably increase the surplus generated by the patented innovations, the fact that taxes affect transactions in intangible assets is of independent interest, quite apart from the usefulness of capital gains taxes as an instrument for identifying the impact of such trade on litigation. Our finding adds to the recent literature that documents the impact of capital gains taxation on the frequency and timing of small business transfers involving tangible assets (Chari, Golosov and Tsyvinski, 2005; Gentry, 2010).

\section{Causal Effect of Trade on Litigation}

The parameter estimates from the regressions in Table 3 allow us to compute the probability that a patent is traded at a specific age, $\widehat{p}_{i t}$. The estimate of $\widehat{p}_{i t}$ can be used to construct an estimate of the probability that NewOwner $r_{i t}=1$, which we denote by $\widehat{P}_{i t}$. To estimate the causal effect of trade on litigation, we use $\widehat{P}_{i t}$ as an instrument for the endogenous variable, NewOwner ${ }_{i t}$. Econometrically, the exogenous variation is derived from the capital gain tax rates, but any monotonic function of this variable can be used as an instrument and $\widehat{P}_{i t}$ is a typical choice when the endogenous variable is binary (Imbens and Angrist, 1994; Lileeva and Trefler, 2010). In all the first-stage regressions, $\widehat{P}_{i t}$ is strongly correlated with the indicator variable NewOwner, and the F-tests of joint exclusion of the instruments do not indicate problems of weak instruments (p-values $<0.01)$.

\footnotetext{
${ }^{30}$ To account for firm level unobservable heterogeneity, we cluster standard errors at firm level. We obtain similar results on taxes, cites and generality both in linear probability models and split sample regressions.
} 
Table 4 presents the parameter estimates using this IV strategy. Column 1 reports estimates when NewOwner is instrumented by the $\widehat{P}_{i t}$ constructed from the probit regression in column 1 of Table 3 . Column 2 shows that the estimated coefficient is nearly identical if the instrument is obtained from the linear probability model. In both regressions the estimated causal effect of a change in ownership on litigation is negative and significant, and the point estimate (in absolute value) is about six times larger than the simple OLS estimate in column 3 of Table 2. This result highlights the importance of controlling for the endogeneity of trade, and indicates a strong positive correlation between NewOwner and the disturbance in the litigation equation (inducing a downward bias if we treat changes in ownership as exogenous).

In column 3 we present similar IV regressions using the sub-sample of traded and litigated patents. In this case too the estimated coefficient on the change in ownership variable is negative and significant, and much larger in absolute value than the OLS estimates in Table $2 .^{31}$

For the full sample, the IV estimate indicates that a change in ownership reduces the annual litigation probability by about 1.1 percentage points. In the sub-sample of traded and litigated patents, the causal effect is an order of magnitude larger, corresponding to a reduction in litigation probability by about 15 percentage points. While the difference in the magnitude of the marginal effect across the two samples is very large, the implied elasticities are fairly similar (i.e., the differences in marginal effects are driven by differences in the mean litigation probability). Evaluated at sample means, the implied elasticity is -0.43 (std.dev. $=0.10$ ) in the full sample, and -0.91 (std.dev. $=0.39$ ) in the restricted sample. ${ }^{32}$

The econometric model (9) assumes a constant effect of trade on litigation. It is tempting to interpret these 2SLS estimates as weighted averages of heterogeneous responses. However, Angrist and Imbens (1995) show that estimates from constant effect models may differ substantially from average heterogeneous effects when there are continuous instruments and covariates. To address this concern, we follow the procedure they suggest and convert the instrument into

\footnotetext{
${ }^{31}$ There is the concern that spurious correlation may arise between low capital gain taxes and litigation because of macro-economic variables. To address this concern we exploit U.S. Bureau of Economic Analysis data on gross state product per capita (GSP) in 1997 dollars. Controlling for GSP, we obtained results very similar to those in our baseline specification. GSP itself is not significantly correlated with patent trade or litigation.

${ }^{32}$ In our empirical setting, these elasticities measure the expected drop in annual litigation rate for a patent that has not yet been traded. In section 6 , we provide a more complete quantification of the effect of trade on litigation by simulating changes in individual tax rates.
} 
a dummy variable. Specifically, we generate the indicator variable Large Tax Difference $_{i t}=1$ if the difference between capital gains and income tax rates is above the 75th percentile of our dataset (19 percentage points). We exploit this binary instrument to estimate the local average treatment effect (LATE): the average effect of a change of ownership for those patents whose owners were induced to sell their patents a the substantial difference between capital gains and income tax rates (Imbens and Angrist, 1994). The average treatment effect is "local" because not all patent owners are induced by the instrument to sell the patent.

In column 4 we present the estimates from the Angrist-Imbens procedure. ${ }^{33}$ The (unreported) first-stage regressions shows a strong positive correlation between Large Tax Difference $_{i t}$ and NewOwner (p-value <0.01). The second-stage LATE estimates indicates that a change in ownership reduces the annual litigation probability by about 3.3 percentage points. While the magnitude of the effect is larger than the one obtained in the constant effects model, the confidence intervals of the two coefficients overlap. Thus, in our setting the estimates of the simple IV model do not differ substantially from the mean of the heterogeneous responses.

The estimated LATE measures the effect of trade on the unidentifiable sub-population of patents that change ownership because of a change in capital gains taxation. Thus it is difficult to map the coefficients estimated in Table 4 to reductions in litigation rates for the average patent in our sample. A plausible assumption is to consider those sample patents that are litigated but not traded as "at risk" of being affected by a change in taxation. For these patents, the estimated LATE from column 4 implies a reduction in the annual litigation rate of about 32 percent. ${ }^{34}$

\footnotetext{
${ }^{33}$ The LATE is estimated as a two-stage least square regression with the endogenous variable instrumented by the dummy instrument and instrument-covariate interactions. For details on the procedure see Angrist and Imbens (1995; Theorem 3) and Lileeva and Trefler (2010).

${ }^{34}$ Specifically, the average annual probabiliy of litigation among patents that are litigated (but not traded) at some point in their life is 0.103 . Thus the percentage change implied by the estimate LATE is equal to $-0.033 / 0.103=-0.32$. We obtain very similar results using the 90 th percentile (30 percentage points): the LATE coefficient is 0.035 ( $\mathrm{p}$-value $=0.04)$.
} 


\section{$5 \quad$ Heterogeneous Effects of Trade on Litigation}

\section{Estimation and Results}

The econometric model developed in the previous section assumes that the treatment effect of trade on litigation is identical across all patent transactions. However, the underlying motivation for transactions may vary, with the gains from trade coming from a variety of sources with different implications for post-trade litigation. Therefore, we now extend the model to allow for heterogeneous treatment effects as follows:

$$
\begin{aligned}
L_{i t}\left(T_{i t}\left(Z_{i t}\right)\right. & =1)=\alpha_{i}+\theta_{i}+\lambda_{\tau}+a_{t}+u_{i t} \\
L_{i t}\left(T_{i t}\left(Z_{i t}\right)\right. & =0)=\theta_{i}+\lambda_{\tau}+a_{t}+u_{i t} \\
T\left(Z_{i t}\right) & =\left\{\begin{array}{lll}
0 & \text { if } & P\left(Z_{i t}\right)<v_{i t} \\
1 & \text { otherwise }
\end{array} \text { and } T_{i t-1}=0\right.
\end{aligned}
$$

where $\theta_{i}$ are patent fixed effects, $a_{t}$ and $\lambda_{\tau}$ are patent age and year effects. We assume that $\alpha_{i}$ can be decomposed into a common component $(\bar{\alpha})$ and a random component $\left(\psi_{i}\right): \alpha_{i}=\bar{\alpha}+\psi_{i}$. The heterogeneous effect of new ownership on litigation is

$$
L_{i t}\left(T_{i t}=1\right)-L_{i t}\left(T_{i t}=0\right)=\bar{\alpha}+\psi_{i}
$$

Consider an increase in the value of the technology that makes the patent both more likely to be traded ( $\operatorname{small} v_{i t}$ ) and more likely to be litigated after trade (high $\psi_{i}$ ). Together these imply that we should observe a negative correlation between $\psi_{i}$ and $v_{i t}$, and thus a negative correlation between $v_{i}$ and the effect of trade on litigation. More formally we should expect $E\left(\bar{\alpha}+\psi_{i} \mid v_{i t}\right)$ to be decreasing in $v_{i t}$. Because $v_{i t}$ is not observed it is not possible to condition on it. Nonetheless, for an inventor that is just indifferent between trading and not trading, it must be that $P\left(Z_{i t}\right)=v_{i t}$. Exploiting this equality, we obtain the marginal treatment effect $E\left(\bar{\alpha}+\psi_{i} \mid P\left(Z_{i t}\right)\right)$, which corresponds to the (heterogenous) effect of trade on litigation for patents that are traded because of the instrument. Heckman and Vytlacil (1999) provide a formal treatment, where they show that

$$
E\left(\bar{\alpha}+\psi_{i} \mid P=v_{i t}\right)=\left.\frac{\partial E\left(L_{i t} \mid P\right)}{\partial P}\right|_{P=v_{i t}}
$$

and establish identification of the marginal treatment effect. Specifically, for any patent, if $T_{i t}=1$ we observe $L_{i t}\left(T_{i t}=1\right)$ and if $T_{i t}=0$ we observe $L_{i t}\left(T_{i t}=0\right)$. Thus the observed 
litigation is

$$
\begin{aligned}
L_{i t} & =L_{i t}\left(T_{i t}=1\right) T_{i t}+L_{i t}\left(T_{i t}=0\right)\left(1-T_{i t}\right) \\
& =\left(\bar{\alpha}+\psi_{i}\right) T_{i t}+\theta_{i}+\lambda_{t}+a_{i t}+u_{i t} .
\end{aligned}
$$

The marginal treatment effect $(M T E)$ can be computed by estimating the expected litigation conditional on $P, E\left(L_{i t} \mid P\right)$. Let $\widehat{P}$ be our estimate of the probability that a patent is not owned by the initial inventor. Substituting this into the observed litigation equation, we obtain a partially linear model

$$
E\left[L_{i t} \mid \widehat{P}_{i t}\right]=E\left[\left(\bar{\alpha}+\psi_{i}\right) T_{i t} \mid \widehat{P_{i t}}\right]+\theta_{i}+\lambda_{t}+a_{i t}
$$

The derivative of (12) can be semi-parametrically and non-parametrically estimated in order to obtain the marginal treatment effect. For the semi-parametric estimation, we follow Carneiro, Heckman, and Vytlacil (2010) and approximate $E\left[\left(\bar{\delta}+\psi_{i}\right) T \mid \widehat{P}_{i t}\right]$ with a third order degree polynomial, obtaining

$$
E\left[L_{i t} \mid \widehat{P}_{i t}\right]=c_{1} \widehat{P}_{i t}+c_{2}\left(\widehat{P}_{i t}\right)^{2}+c_{3}\left(\widehat{P}_{i t}\right)^{3}+\theta_{i}+\lambda_{t}+a_{i t}
$$

which implies a $M T E$ equal to $c_{1}+2 \widehat{P}_{i t} c_{2}+3 c_{3}\left(\widehat{P}_{i t}\right)^{2}{ }^{35}$ For the non-parametric approach, we follow the multistep procedure developed by Heckman, Ichimura, Smith and Todd (1998) and Carneiro, Heckman, and Vytlacil (2010) (see appendix for details). ${ }^{36}$

Figure 2 shows the semi-parametric estimation of the $M T E$ for the entire sample. ${ }^{37}$ The horizontal axis depicts the estimated probability that the patent is not owned by the original inventor, $\widehat{P}$. The vertical axis shows the effect of trade on litigation for different values of $\widehat{P}$ (dashed lines are 95 percent bootstrapped confidence intervals). The support for $\widehat{P}$ goes up to 0.15 , which corresponds to the 99 th percentile for the measure. The absolute value of the

\footnotetext{
${ }^{35}$ A simple test of heterogeneity suggested by Carneiro et. al. (2010) involves testing the null hypothesis that the coefficients of the second and third order are jointly equal to zero. The $F$-statistic for $\widehat{c}_{2}=\widehat{c}_{3}=0$ is 24.28 $(p<0.01)$ in the sample for litigated and traded patents and $13.61(p<0.01)$ in the full sample.

${ }^{36}$ Specifically, the first part of the procedure involves estimating the litigation equation non-parametrically. This is a non-parametric counterpart of the $I V$ estimates and it involves the use of local linear regressions. The second part of the procedure involves numerically differentiating the estimated $E\left[L \mid \widehat{P}_{i t}\right]$.

${ }^{37}$ For the large sample, only the semi-parametric MTE could be estimated because running local linear regressions in a panel with more than 2 million observations is infeasible with the available computer hardware.
} 
estimated marginal treatment effect is monotonically increasing in $\widehat{P}$. Patents with low value of $\widehat{P}$ are those that, given their observables, are unlikely to have changed ownership (e.g. patents that are not highly cited or with low generality index). The small (or insignificant) values of the $M T E$ in this range show that, if a change in capital gain taxes induced the owner of one of these patents to sell, the change in litigation risk would be negligible. Conversely, patents with high $\widehat{P}$ are those at high risk of being traded. For these patents the MTE is negative, indicating a substantial drop in the likelihood of litigation from transfer of ownership. The MTE becomes statistically significant for values of $\widehat{P}$ above 0.03 that roughly correspond to the median of the $\widehat{P}$ distribution. About 48 percent of sample observations have values of $\widehat{P}$ between 0.03 and $0.1 .^{38}$

Figure 3 reports the non-parametric estimates of the $M T E$ for the sub-sample of patents that are traded and litigated. The support for $\widehat{P}$ differs from the one in the previous figure because the estimated probability of a change in ownership is greater in the sample where all patents are traded. Also in this case we find that the absolute value of the estimated effect is monotonically increasing in $\widehat{P}$ and statistically significant for values of $\widehat{P}$ greater than 0.5 . The figure looks similar if we estimate the $M T E$ with the semi-parametric procedure employed for the larger sample.

These results point to two important conclusions. First, the main impact of trading in patent rights, over most of the range of $\widehat{P}$, is to reduce litigation risk, suggesting that comparative advantage in patent enforcement may be more important than comparative advantage in commercialisation, at least for transfers involving individually-owned patents. Second, the results show that patents with larger estimated (enforcement) gains from trade are in fact those with the highest predicted likelihood of changing ownership. This suggests that the market for innovation reallocates patent rights efficiently, at least in this sense.

\footnotetext{
${ }^{38}$ Two points should be noted. First, to compare the MTE's with the 2SLS estimate of the LATE, we split the distribution of $\widehat{P}$ into seven adjacent bins and computed a weighted average of the MTEs evaluated at the bin mid-points, with weights equal to the fraction of observations in each bin. The average is equal to -0.013 , which is very close to our 2SLS estimates.

Second, to assess what fraction of the variation in $\widehat{P}$ is generated by the instrument, we re-estimated the probability of trade using only variation in capital gains taxes and fixing all other covariates at their sample means. The resulting distribution is approximately uniform, with a support ranging from zero to 0.08, which is approximately the 90th percentile of the distribution of $\widehat{P}$. This confirms that the instrument generates substantial variation in the predicted change in ownership.
} 


\section{Unbundling the Marginal Treatment Effect}

We have shown that the effect of trade on litigation is heterogenous, and that the effect reduces litigation more strongly for patents at greater risk of being traded. This suggests that the nature of the transactions varies and that there is a particular type of sorting: patents less likely to be traded (low values of $\widehat{P}$ ) being more likely in transactions based on commercialisation advantages, and patents with high values of $\widehat{P}$ more likely to be in transactions driven by enforcement gains. To understand this sorting better, in this section we unbundle the marginal treatment effect and relate it to observable characteristics of the transaction.

To do this, we need information on patent buyers. The USPTO reassignment data contain non-standardized names of the buyers, so buyer characteristics must be manually recovered. We perform this manual match for the 569 patents that were both traded and litigated at least once in their lifetime. For each of these patents, we constructed the size of the portfolio of the buyer, defined as the number of patents obtained in the twenty years before the trade occurs. Our matching shows that most transactions involve trade from an individual owner to a firm (only 11.4 percent of cases involve two individuals). The distribution of buyer portfolio size is highly skewed. The median portfolio size for acquiring firms is one patent, the 75th percentile is three, and the mean is 106.1.

We use the buyer portfolio to construct two variables to capture the two basic motivations for transactions: enforcement gains and commercialisation (product market) gains. ${ }^{39}$ The first variable, LargeBuyer, is equal to one if the buyer's portfolio includes at least eight patents at the time of the transaction (i.e., if the buyer had that number of patents granted in the preceding twenty years). In our sample there are 24 transactions (about five percent) involving large buyers. Lanjouw and Schankerman (2004) show that firms with large patent portfolios are less likely to file a suit on any individual patent in their portfolios, controlling for patent characteristics, and argue that this reflects their ability to resolve disputes 'cooperatively'

\footnotetext{
${ }^{39}$ We also examine the possibility that changes in ownership may simply be the way patent disputes are settled, rather than reflecting an efficient reallocation to entities that are less likely to resort to courts. To do this we compare the names of the parties trading a patent with those involved in litigation. There is very little overlap: in only 20 patent cases (3.5 percent of the sample of litigated and traded patents) does a patent transfer follow a suit filed by the same parties. This indicates that the main effect of trade is through comparative advantage in enforcement, and not through facilitating settlement of an existing dispute.
} 
without resorting to the courts. Building on this idea, we expect "enforcement gains" (reduction in litigation) to be greater for patents acquired by large buyers.

The second variable is designed to capture transactions where the traded patent is a good match for the technology profile of the buyer, where comparative advantage in manufacturing or marketing are more likely to be realized. We define TechFit as a dummy variable equal to one if the acquired patent belongs to the technology area to which the plurality of the buyer's patents are assigned. To do this we use the 36 technology sub-categories defined in Hall et. al. (2001). The TechFit measure is equal to one for 140 patents (about 25 percent of the sample). The hypothesis is that in such cases the product market gains from the transaction will be larger, and thus that such transactions tend to raise, not lower, litigation risk.

Table 5 presents instrumental variable regressions that examine how buyer portfolio size and patent fit affect the impact of trade on litigation. Column 1 confirms that patents traded to small entities that fit well in the portfolio experience an increase in litigation after they are traded. These are transactions where we expect product market gains to be important and enforcement gains negligible. In sharp contrast, column 2 shows that the largest reduction in litigation rates occurs when patents are traded to large entities with low fit in the buyer patent portfolio, where enforcement gains are large and product market gains are small. Columns 3 and 4 show that trade is associated with a reduction in litigation of smaller magnitude for transactions where both sources of gains (or none) are present. In column 5 we confirm the results using the pooled sample and interacting the traded indicator with the dummies for large portfolio and patent fit. ${ }^{40}$

Table 6 shows that these results are robust to a number of alternative specifications. In column 1 we increase the large buyer threshold from 8 to 12 patents. Columns 2-4 use alternative constructions of the TechFit measure. In the baseline regression we set TechFit $=1$ when the buyer is an individual (in such cases we cannot measure the portfolio size). Column 2 uses the alternative TechFit $=0$ in such cases. In column 3 we employ a TechFit measure

\footnotetext{
${ }^{40}$ The regression in column 5 is a constrained version of those in columns 1-4, where period dummies are the same across the different samples. In a more general specification we do not reject the hypothesis that the period dummies are the same across the four groups of transactions. In column 5 we allow the age dummies to differ across the samples because the data strongly indicated differences in the impact of these dummies in the first stage regression.
} 
constructed using a finer technology classification (we move from 36 technology sub-categories to about 400 USPTO patent classes). Finally, in column 4 we use a citations-based TechFit measure. Specifically, we define TechFit $=1$ if either the acquired patent cites one of the patents of the buyer or if the patents of the buyer cite the acquired patent.

In all these regressions the interaction between the NewOwner indicator and TechFit is positive and significant, and the interaction with the LargeBuyer dummy is negative and significant. These results are consistent with the theoretical framework developed in Section 2, where the relative magnitude of product market and enforcement gains determine whether a change in ownership has a positive or negative impact on patent litigation.

These unbundling results provide more insight into the pattern of marginal treatment effects documented in Figures 2 and 3. Our estimates suggest that patents with low values of $\widehat{P}$ are more likely to be involved in transactions driven by product market gains, and patents with high $\widehat{P}$ are more likely to be involved in transactions driven by enforcement gains. To explore this idea further, we look at the types of transactions at each level of $\widehat{P}$. Controlling for patent age, our data show that as $\widehat{P}$ increases there is a decline in the number of trades to small buyers with high TechFit, and a corresponding increase in the low TechFit trades. For example, for patent age 5, about 30 percent of patents in the first quartile of the $\widehat{P}$ distribution are involved in high fit/small buyer transactions. The fraction drops to 16 percent for patents in the fourth quartile of the $\widehat{P}$ distribution. Among those patents, the fraction of low fit trade is about 65 percent in the first quartile, but 82 percent in the fourth quartile of the $\widehat{P}$ distribution.

\section{Product Market Gains or Patent Trolls?}

The unbundling exercise shows a positive association between trade and litigation only for patents traded to small entities that fit well in the buyer's portfolio. This finding is consistent with the model developed in Section 2, where higher litigation rates are generated by product market gains. A possible alternative explanation for this finding is that the patents in this sub-sample are acquired by small, specialized patent assertion entities (a.k.a. patent trolls).

We conduct a series of empirical tests to distinguish between these two competing explanations. Business press, legal studies and anecdotal evidence suggest that trolls tend to be common in a few industries, specifically those with complex technologies involving many 
patented inputs: computers, communication and electronics. We check whether these industries are over-represented in the high-fit/small-buyer sub-sample by testing differences between the technology composition of these patents and the technology composition of the other traded and litigated patents. Mean comparison tests provide no evidence of industry specialization in the high-fit/small-buyer sub-sample. This result is confirmed by a multinomial logit regressions relating the four categories of patent transactions to industry dummies. ${ }^{41}$

Second, we examine whether the increase in litigation observed in the small-buyer/highfit sub-sample is driven by serial buyers. From the USPTO re-assignment data, we retrieve the number of patents acquired by each buyer in the sub-sample during the sample period. The distribution is highly skewed (the median number of acquired patents is 2 , the mean is 9 , and the 95th percentile is 20). We generate a dummy variable capturing buyers that acquired at least 8 patents (the maximum portfolio size in this sub-sample). This dummy is equal to one for 13.5 percent of the buyers in the sub-sample. OLS and two-stage least square regressions where the dummy is interacted with NewOwner show no evidence that the increase in litigation is driven by serial buyers. ${ }^{42}$

Finally, we examine whether the increase in litigation is driven by a few serial litigants. To do this, we compute the number of patent cases in which each buyer is involved as plaintiff during the sample period. Of the 116 buyers, 76 are involved in no patent cases, and only five buyers are involved in more than three cases. OLS and two-stage least squares regressions that interact the number of cases with NewOwner show no evidence that the increase in litigation is driven by serial litigants.

Overall these exercises suggest that the increase in litigation rates in the high-fit/smallbuyer transactions is more likely to be driven by product market gains than by the activity of patent trolls. Together with our finding that trade reduces litigation risk for all the other

\footnotetext{
${ }^{41}$ The fraction of patents in computers and communication (NBER category 2) is 0.11 in the high-fit/smallbuyer sub-sample and 0.09 for the other traded and litigated patents, and the difference is not statistically significant ( $\mathrm{p}$-value=0.52). Similarly, the fraction of patents in electrical and electronics (NBER category 4 ) is 0.08 in the high-fit/small-buyer sub-sample and 0.10 for the other patents, and again the difference is not statistically significant ( $\mathrm{p}$-value $=0.62)$.

${ }^{42}$ Similar results are obtained with less restrictive definitions of serial buyers. For example, we generate a dummy capturing buyers that acquire more patents that those granted to them (77.55 percent of buyers in the sub-sample) and also in this case, interacting this variable with NewOwner, we find no evidence that the increase in litigation is driven by serial buyers.
} 
transaction types, this result indicates that during our sample period trolls do not play a substantial role in the market for individually-owned patents. This finding does not imply that trolls are unimportant in the patent marketplace. Our data, which cover only patents owned by individual inventors during the period 1983-2000, do not allow us to draw this conclusion. It may be that patent assertion entities are more active in the market for company-owned patents. Moreover, while there is documentary evidence of patent trolls throughout the 20th century (Resis, 2006), their activity may have intensified in the post-2000 period. We plan to investigate these issues in future research.

\section{Simulating Tax Effects on Trading and Litigation}

We have shown that capital gains taxes affect patent trading and that these transactions affect post-trade litigation risk. In this section we use our parameter estimates to simulate the impact of various tax scenarios on the frequency of patent transactions and litigation.

Let $\tau^{G}$ denote the capital gain tax rate, which we assume is constant for the entire life of a patent. Let $P_{t}\left(\tau^{G}\right)$ denote the probability that the patent has been traded by age $t, L_{0 t}$ be the likelihood of being involved in at least one dispute at age $t$ if the patent is owned by the initial inventor, and $L_{1 t}$ be the likelihood of being involved in at least one dispute at age $t$ if ownership has changed. Then the expected number of years in which at least one dispute is filed is

$$
\begin{aligned}
E\left(L\left(\tau^{G}\right)\right) & =\sum_{t=1}^{T}\left(1-P_{t}\left(\tau^{G}\right)\right) L_{0 t}+\sum_{t=1}^{T} P_{t}\left(\tau^{G}\right) L_{1 t} \\
& =\sum_{t=1}^{T} L_{0 t}+\sum_{t=1}^{T} P_{t}\left(\tau^{G}\right)\left(L_{0 t}-L_{1 t}\right) .
\end{aligned}
$$

The estimates in Tables 3 and 4 can be used to compute $E\left(L\left(\tau^{G}\right)\right)$ for the average patent in our sample. We measure $L_{0 t}$ as the predicted litigation probability for a patent of age $t$ that has not changed ownership, using column 1 from Table 4. $L_{0 t}-L_{1 t}$ is computed with the IV estimate in the first column of Table $4 . P_{t}\left(\tau^{G}\right)$ is the predicted probability of trade for different levels of capital gain taxes $\tau^{G}$, constructed using the estimates in column 1 from Table 3, and evaluated at sample means.

We compute $E\left(L\left(\tau^{G}\right)\right)$ for different tax scenarios. In the baseline scenario we assume 
$\tau^{G}=29.2$ (percent), which is the average value in our sample and similar to the combined (state plus federal) tax rate faced by an individual in Texas in 1995. In the second, low tax scenario we set $\tau^{G}=20$, which is the lowest rate in our sample and is the combined rate faced in Florida in 1985. In the third, high tax scenario $\tau^{G}=40$, which is close to the highest rate in our sample that was charged in California in 1997. In the last two scenarios we study the impact of removing the differential tax treatment of capital gains. First, we increase the capital gains rate to be equal to the (personal) income tax rate. Second, we equate the two rates at the lower, capital gains rate. In all these exercise corporate tax rates are kept at their sample mean.

Table 7 summarizes the results. In the baseline scenario $E(L(\tau))$ is 0.013 . Multiplying this number by the average number of disputes filed in each year in which the patent is litigated (1.2 in our sample) and adjusting for litigation under-reporting using the weights in Lanjouw and Schankerman (2001), we can translate $E(L(\tau))$ into a number of predicted disputes. Our computations predicts about 36 disputes every 1,000 patents. This estimate, computed using an entirely independent method, is very similar to the litigation level estimated in Lanjouw and Schankerman (2001), which for individuals is 35 disputes per 1,000 patents.

In the low tax scenario - representing a reduction in the capital gains rate by 9.2 percentage points - the number of traded patents nearly doubles and this generates a 36 percent reduction in the number of disputes (to about 23 per 1,000 patents). In the high tax scenario an increase in the capital gains rate by 11 percentage points - there is a 45 percent reduction in the number of traded patents with an associated 22 percent increase in the number of disputes. Equalizing capital gains and income tax rates is associated with a contraction in the frequency of trade and an increase in litigation. The magnitude of the effect depends on whether the equality is reached by an increase in capital gains rate or a reduction in the income tax rate. The increase in litigation rates is stronger when capital gains rates are increased to the average level of income rates in our sample (42.6 percent). These computation exercises confirm that capital gains taxes have a powerful impact on the market for patents and the litigation risk associated with the enforcement of those patent rights. 


\section{Conclusions}

In this paper we study how the market for patents affects the enforcement of patent rights. Conventional wisdom associates the reallocation of patent rights through trade with comparative advantages in commercializing the innovation. The associated product market gains from trade should increase litigation risk for traded patents. We identify a new source of gains from trade, comparative advantage in patent enforcement, and show that this mechanism reduces patent litigation. Using data on trade and litigation of individually-owned patents, and exploiting variation in capital gains tax rates across states and over time as an instrumental variable, we identify the causal effect of changes in patent ownership on litigation rates.

There are three key empirical findings in the paper. First, capital gains taxes strongly affect market transactions in patent rights granted to individual inventors. Second, the reallocation of these patent rights reduces litigation risk for individually-owned patents, on average, indicating that enforcement gains are more important than product market gains for such patents. Third, the marginal treatment effect of trade on litigation is heterogeneous. Patents with larger potential gains from trading are those with the highest estimated probability of changing ownership, suggesting that market reallocates patent rights efficiently. Moreover, the impact of trade is related to transaction characteristics - specifically, the size of the buyer's patent portfolio and the technological fit of the patent in that portfolio. Sales by individual inventors to other individuals or small firms do not reduce post-trade litigation risk, while sales to firms with larger patent portfolios significantly reduce such risk. Trade increases litigation risk more when the patent is a better technological fit in the buyer's existing portfolio, where we expect greater potential for product market gains from the transfer. Finally, we do not find any evidence that patent trolls play a substantial role in our sample of transactions involving individually-owned patents during the period 1983-2000. Whether this conclusion would apply to corporate patent transactions, or the last decade, is left for future research.

The findings in this paper indicate that a well-functioning market for innovation is important for allocating patent rights efficiently ex post, and that taxation affects this process. As long as small innovators can appropriate part of the gains from patent trading, this market also increases their ex ante incentives to innovate. 


\section{References}

[1] ACIR American Council on Intergovernmental Relations (1982-1995). Significant Features of Fiscal Federalism, Budget processes and Tax systems. Government Printing Office, Washington, DC.

[2] Angrist, Joshua (2001), "Estimation of Limited Dependent Variable Models with Dummy Endogenous Regressors: Simple Strategies for Empirical Practice", Journal of Business 6 Economics Statistics 19: 2-16

[3] Angrist, Joshua and Guido Imbens (1995), "Two-Stage Least Squares Estimation of Average Causal Effects in Models with Variable Treatment Intensity", Journal of the American Statistical Association 90: 431-442

[4] Arora, Ashish, Andrea Fosfuri and Alfonso Gambardella (2001), Markets for Technology: The Economics of Innovation and Corporate Strategy (Cambridge, MA: MIT Press)

[5] Arora, Ashish and Marco Ceccagnoli (2006), "Patent Protection, Complementary Assets and Firms' Incentives for Technology Licensing," Management Science 52: 293-308

[6] Bessen, James and Michael J. Meurer (2008), Patent Failure (Princeton: Princeton University Press)

[7] Carneiro, Pedro, James Heckman and Edward Vytlacil (2010) "Evaluating Marginal Policy Changes and the Average Effect of Treatment for Individuals at the Margin," Econometrica 78: 377-394

[8] Chari, Varadarajan, Mikhail Golosov and Aleh Tsyvinski (2005), "Business Start-ups, the Lock-in Effect, and Capital Gains Taxation," Working paper, Yale University

[9] CSG Council of State Governments (1996-2000). Book of the States, Washington DC.

[10] Desai, Mihir and William Gentry (2004), "The Character and Determinants of Corporate Capital Gains," in James M. Poterba, ed., Tax Policy and the Economy (Cambridge, MA: MIT Press), 1-36 
[11] Dykeman, David and Daniel Kopko (2004), "Recording Patent License Agreements in the USPTO," Intellectual Property Today, August Volume:18-19

[12] Federal Trade Commission (2003), "The Evolving IP Marketplace: Aligning Patent Notice and Remedies with Competition," Washington DC.

[13] Feenberg, Daniel Richard and Elizabeth Coutts (1993), "An Introduction to the TAXSIM Model", Journal of Policy Analysis and Management 12: 189-194

[14] Galasso, Alberto and Mark Schankerman (2010), "Patent Thickets, Courts and the Market for Innovation", RAND Journal of Economics 41: 472-503

[15] Gans, Joshua and Scott Stern (2000), "Incumbency and R\&D Incentives: Licensing the Gale of Creative Destruction" Journal of Economics and Management Strategy 9: 485-511

[16] Gans, Joshua, David Hsu and Scott Stern (2002), "When Does Start-Up Innovation Spur the Gale of Creative Destruction?" RAND Journal of Economics 33: 571-586

[17] Gentry, William (2010), "Capital Gains Taxation and Entrepreneurship," Working paper, Williams College

[18] Hall, Bronwyn, Adam Jaffe and Manuel Tratjenberg (2001), "The NBER Patent Citation Data File: Lessons, Insights and Methodological Tools," NBER Working Paper 8498

[19] Hall, Bronwyn and Rosemarie Ziedonis (2001), "The Patent Paradox Revisited: An Empirical Study of Patenting in the US Semiconductor Industry, 1979-95," RAND Journal of Economics, 32(1) : 101-128

[20] Heckman, James, Hidehiko Ichimura, Jeffrey Smith and Petra Todd (1998), "Characterizing Selection Bias Using Experimental Data," Econometrica 66: 1017-1098

[21] Heckman, James and Edward Vytlacil (1999), "Local Instrumental Variables and Latent Variable Models for Identifying and Bounding Treatment Effects," Proceedings of the National Academy of Sciences 96: 4730-4734

[22] Imbens, Guido and Angrist Joshua (1994), Identification and Estimation of Local Average Treatment Effects, Econometrica 62, 467-476 
[23] Lanjouw, Jean O. and Josh Lerner (2001), "Tilting the Table? The Predatory Use of Preliminary Injunctions," The Journal of Law and Economics, 44(2), 573-603

[24] Lanjouw, Jean and Mark Schankerman (2001), "Characteristics of Patent Litigation: A Window on Competition," RAND Journal of Economics, 32: 129-151

[25] Lanjouw, Jean and Mark Schankerman (2004), "Protecting Intellectual Property Rights: Are Small Firms Handicapped?," Journal of Law and Economics, 47: 45-74

[26] Lemley, Mark and Carl Shapiro (2007), "Patent Hold-Up and Royalty Stacking," Texas Law Review 85: 1991-2049

[27] Lerner, Josh (1995), "Patenting in the Shadow of Competitors," Journal of Law and Economics 38, 463-96

[28] Lileeva, Alla and Daniel Trefler (2010), "Improved Access to Foreign Markets Raises PlantLevel Productivity ... for Some Plants", Quarterly Journal of Economics 125: 1051-1099

[29] Mann, Ronald J. (2005), "Do Patents Facilitate Financing in the Software Industry?", Texas Law Review 83: 961-973

[30] Maine, Jeffrey and Xuan-Thao Nguyen (2003), Intellectual Property Taxation: Transaction and Litigation Issues (Washington D.C.: The Bureau of National Affairs Inc.)

[31] Maine, Jeffrey and Xuan-Thao Nguyen (2010), "Equity and Efficiency in Intellectual Property Taxation," Brooklyn Law Review 76: 1-63

[32] Resis, Robert (2006), "History of the Patent Troll and Lessons Learned", Intellectual Property Litigation 17: 1-6

[33] Rivers R. Douglas, and Quang H. Vuong (1998), "Limited Information Estimators and Exogeneity Tests for Simultaneous Probit Model," Journal of Econometrics, 39: 347-65

[34] Serrano, Carlos J. (2010), "The Dynamics of the Transfer and Renewal of Patents," RAND Journal of Economics 41: 686-708

[35] Teece, David (1986), "Profiting from Technological Innovation: Implications for Integration, Collaboration, Licensing, and Public Policy," Research Policy, 15, 285-305 


\section{Appendix: Details on Non-Parametric Estimation}

This section describes the details of the non-parametric estimation of the marginal treatment effect. Our approach is based on a multistep, non-parametric procedure of Heckman, Ichimura, Smith and Todd (1998) and Carneiro, Heckman, and Vytlacil (2010). We extend their procedure to a panel data setting in order to account for individual/patent fixed effects.

The first part of the procedure involves estimating the litigation equation non-parametrically. This is a non-parametric counterpart of the IV estimates in Table 4.

1. STEP 1. Regress each of the variables in the vector of covariates $X$ on $\widehat{P}$ using local linear regression. In our setting this involves running multiple regressions. In particular, we run a regression for each age dummy on $\widehat{P}$, a regression for each calendar dummy on $\widehat{P}$, and finally another regression of income tax rates on $\widehat{P}$. The regressions were run in STATA 10 using the command lpoly.

2. STEP 2. Let $\widehat{\varepsilon}_{X}$ be the residuals and vector of residuals from the regression in step 1 . Regress $L$ on $\widehat{\varepsilon}_{X}$ using OLS with patent fixed effects in order to obtain an estimate of the vector $\beta_{0}$.

3. STEP 3. Let $\widehat{\varepsilon}$ be an estimate of the residual from the previous OLS regression (accounting for the patent fixed effects). This is an estimate of $\beta_{1} \widehat{P}+E\left[\left(\bar{\alpha}+\psi_{i}\right) T \mid \widehat{P}\right]$. Regressing $\widehat{\varepsilon}$ on $\widehat{P}$ using local linear regression allow us to obtain a non-parametric estimate of $\widehat{\varepsilon}(\widehat{P})$.

Putting all this together, we construct an estimate of $E[L \mid \widehat{P}], \widehat{E[L \mid \widehat{P}]}=\widehat{\beta_{0}} X+\widehat{\mu}_{i}+\widehat{\varepsilon}(\widehat{P})$.

The second part of the procedure involves numerically differentiating $\widehat{E[L \mid \widehat{P}]}$. To do so, we divide observations into groups, based either on the deciles of the distribution of $\widehat{P}$ or the absolute value of $\widehat{P}$. Recall that the variable component of $\widehat{E[L \mid \widehat{P}]}$ with respect to $\widehat{P}$ is $\widehat{\varepsilon}(\widehat{P})$. The mean of $\widehat{\varepsilon}(\widehat{P})$ was calculated for each of these groups. The derivative of $\widehat{\varepsilon}(\widehat{P})$ were obtained by finite differencing across neighboring groups. The confident intervals of the marginal treatment effects were obtained using 50 bootstrap iterations (seed $=123$ in STATA $10)$. 
TABLE 1. SUmmary Statistics

Panel A. Patent Trade and Litigation

\begin{tabular}{|c|c|c|c|c|c|c|c|}
\hline & \multicolumn{3}{|c|}{ Patents Not Traded } & \multicolumn{2}{|c|}{ Patents Traded } & \multicolumn{2}{|l|}{ Total } \\
\hline & & $\mathrm{N}$ & col. perc. & $\mathrm{N}$ & col. perc. & $\mathrm{N}$ & col. perc. \\
\hline \multirow[t]{2}{*}{ Patents Not Litigated } & $\mathrm{N}$ & 284,281 & 99.49 & 13,038 & 95.82 & 297,319 & 99.31 \\
\hline & row perc. & 95.61 & & 4.39 & & & \\
\hline \multirow[t]{2}{*}{ Patents Litigated } & $\mathrm{N}$ & 1,468 & 0.51 & 569 & 4.18 & 2,037 & 0.69 \\
\hline & row perc. & 72.07 & & 27.93 & & & \\
\hline \multirow[t]{2}{*}{ Total } & $\mathrm{N}$ & 285,749 & & 13,607 & & 299,356 & \\
\hline & row perc. & 95.45 & & 4.55 & & & \\
\hline
\end{tabular}

Panel B. Capital Gains and Income Tax Rates

\begin{tabular}{|c|c|c|c|c|c|c|c|c|c|c|c|c|}
\hline \multicolumn{5}{|c|}{ Capital Gains Tax Rates } & \multicolumn{4}{|c|}{ Income Tax Rates } & \multicolumn{4}{|c|}{ Corporate Tax Rates } \\
\hline Period & Mean & Std. Dev. & Min & Max & Mean & Std. Dev. & Min & Max & Mean & Std. Dev. & Min & Max \\
\hline 1982-1986 & 21.4 & 1.2 & 20 & 27 & 52.7 & 1.9 & 50 & 56.7 & 52.6 & 3.1 & 46 & 58 \\
\hline 1987-1991 & 31.6 & 2.1 & 28 & 37 & 34.4 & 4.5 & 28 & 44.6 & 46.5 & 3.3 & 39 & 54.5 \\
\hline 1992-1996 & 32.4 & 1.9 & 28.9 & 37 & 42.4 & 3.9 & 31.9 & 48.1 & 45.8 & 3.1 & 39 & 51.2 \\
\hline $1997-2001$ & 26.9 & 5.6 & 21.2 & 40.3 & 43.9 & 1.8 & 40.3 & 46.9 & 45.8 & 2.9 & 39 & 51 \\
\hline
\end{tabular}


TABLE 2: Trade and Litigation- Correlations

\begin{tabular}{|c|c|c|c|c|}
\hline & 1 & 2 & 3 & 4 \\
\hline Estimation Method & OLS & OLS & OLS & OLS \\
\hline Dependent Variable & Litigation Dummy & Litigation Dummy & Litigation Dummy & Litigation Dummy \\
\hline NewOwner x 10 & $\begin{array}{l}0.039 * * * \\
(0.003)\end{array}$ & $\begin{array}{c}-0.025^{* * *} \\
(0.004)\end{array}$ & $\begin{array}{c}-0.019 * * * \\
(0.004)\end{array}$ & $\begin{array}{l}-0.056 \\
(0.153)\end{array}$ \\
\hline Patent Fixed Effects & NO & YES & YES & YES \\
\hline Age Dummies & NO & NO & YES & YES \\
\hline Time Period Dummies & NO & NO & YES & YES \\
\hline Sample & Entire Sample & Entire Sample & Entire Sample & $\begin{array}{c}\text { Litigated and Traded } \\
\text { Patents }\end{array}$ \\
\hline Patents & 299,356 & 299,356 & 299,356 & 569 \\
\hline Observations & $2,436,649$ & $2,436,649$ & $2,436,649$ & 6,810 \\
\hline
\end{tabular}

NOTES: Standard errors clustered at patent level are reported in parentheses. Statistical significance: * 10 percent, ** 5 percent, *** 1 percent. Litigation Dummy $=1$ if the patent is involved in at least one case at that age; NewOwner $=1$ when the patent changes ownership for the first time and remains equal to one for the remaining life of the patent. Time Period Dummies: before 1986, 1986-1990, 1991-1995, after 1995. 
TABLE 3: Impact of Taxes on Patent Trading

\begin{tabular}{|c|c|c|c|c|}
\hline & 1 & 2 & 3 & 4 \\
\hline Estimation Method & Probit & OLS & Probit & Probit \\
\hline \multirow[t]{2}{*}{ Dependent Variable } & Trade & Trade & Trade & Trade \\
\hline & Mar. Eff. x $10^{3}$ & Coefficients $\times 10^{3}$ & Mar. Eff. $\times 10^{2}$ & Mar. Eff. x $10^{3}$ \\
\hline \multirow[t]{2}{*}{ Capital Gains Tax Rate } & $-0.204^{* * *}$ & $-0.313^{* * *}$ & $-0.590 * * *$ & -0.147 \\
\hline & $(0.051)$ & $(0.076)$ & $(0.195)$ & (0.631) \\
\hline \multirow[t]{2}{*}{ Income Tax Rate } & $0.132 * *$ & $0.196 * * *$ & 0.196 & 0.391 \\
\hline & $(0.050)$ & $(0.071)$ & $(0.186)$ & $(0.620)$ \\
\hline \multirow[t]{2}{*}{ Corporate Tax Rate } & $-0.063^{* * *}$ & $-0.147^{* * *}$ & $-1.013^{*}$ & -0.373 \\
\hline & $(0.020)$ & $(0.049)$ & $(0.549)$ & $(0.330)$ \\
\hline \multirow[t]{2}{*}{ Patent Citations Received } & $0.061^{* * *}$ & $0.187^{* * *}$ & 0.015 & $0.102 * * *$ \\
\hline & (0.001) & $(0.001)$ & $(0.029)$ & $(0.011)$ \\
\hline \multirow[t]{2}{*}{ Patent Generality } & $0.193^{*}$ & 0.052 & 5.576 & $1.018^{* *}$ \\
\hline & $(0.100)$ & (0.151) & (2.624) & $(0.500)$ \\
\hline \multirow[t]{2}{*}{ Citations x Large Firm } & & & & $-0.159 * * *$ \\
\hline & & & & $(0.030)$ \\
\hline \multirow[t]{2}{*}{ Generality x Large Firm } & & & & -0.750 \\
\hline & & & & $(0.920)$ \\
\hline Sample & $\begin{array}{c}\text { Entire Sample until } \\
\text { Traded }\end{array}$ & $\begin{array}{c}\text { Entire Sample until } \\
\text { Traded }\end{array}$ & $\begin{array}{l}\text { Litigated and } \\
\text { Traded Patents } \\
\text { until Traded }\end{array}$ & $\begin{array}{c}\text { Corporate Patents } \\
\text { until Traded }\end{array}$ \\
\hline Patents & 259743 & 259743 & 558 & 673836 \\
\hline Observations & 2112507 & 2112507 & 3025 & 4281779 \\
\hline
\end{tabular}

NOTES: All regressions include age dummies, year dummies and technology field dummies. Standard errors are clustered at patent level in columns 1-3 and at firm level in column 4. Statistical significance: *10 percent, **5 percent, *** 1 percent. Trade 1 when the patent changes ownership for the first time. Capital Gains Tax Rate: sum of federal and state capital gain tax rates in the state of first inventor. Income Tax Rate: sum of federal and state income tax rates in the state of first inventor. Corporate Tax Rate: weighted average of state corporate taxes with weights constructed using share of patenting in the technology area. Patent Citations Received: truncation-adjusted forward cites. Patent Generality: see Hall et al. (2001). Technology Dummies are generated using the 36 technology sub-categories defined in Hall et al. (2001). Large Firm = 1 if firm obtains more than five patents in the grant year the focal patent. 
TABLE 4: Impact of Trade on Litigation - Instrumental Variable Estimation

\begin{tabular}{|c|c|c|c|c|}
\hline & 1 & 2 & 3 & 4 \\
\hline Estimation Method & 2SLS & 2SLS & 2SLS & 2SLS \\
\hline Dependent Variable & Litigation Dummy & Litigation Dummy & Litigation Dummy & Litigation Dummy \\
\hline NewOwner (Instrumented) & $\begin{array}{l}-0.012^{* *} \\
(0.005)\end{array}$ & $\begin{array}{c}-0.011^{* *} \\
(0.004)\end{array}$ & $\begin{array}{l}-0.211^{* * *} \\
(0.070)\end{array}$ & $\begin{array}{c}-0.033 * * * \\
(0.011)\end{array}$ \\
\hline Sample & Entire Sample & Entire Sample & $\begin{array}{c}\text { Traded and Litigated } \\
\text { Patents }\end{array}$ & Entire Sample \\
\hline Patents & 299356 & 299356 & 569 & 299356 \\
\hline Observations & 2436649 & 2436649 & 6810 & 2436649 \\
\hline INSTRUMENT & $\begin{array}{c}\hat{P} \\
\text { estimated with probit }\end{array}$ & $\begin{array}{c}\hat{P} \\
\text { estimated with OLS }\end{array}$ & $\begin{array}{c}\hat{P} \\
\text { estimated with probit }\end{array}$ & $\begin{array}{c}\text { Large Tax Difference } \\
\text { Dummy }\end{array}$ \\
\hline
\end{tabular}

NOTES: All regressions include age dummies, period dummies and patent fixed effects. Standard errors clustered at patent level are reported in parentheses. Statistical significance: * 10 percent, ** 5 percent, *** 1 percent. Litigation Dummy $=1$ if the patent is involved in at least one case at that age; NewOwner $=1$ when the patent changes ownership for the first time and remains equal to one for the remaining life of the patent. Time Period Dummies: before 1986, 1986-1990, 1991-1995, after 1995. P is the estimated probability of not being owned by the original inventor.

Large Tax Difference Dummy =1 if difference between income tax rates and capital gain tax rates is above the 75 th percentile. 
TABLE 5: The Roles of Buyer Portofolio Size and Patent Fit - Instrumental Variable Estimation

\begin{tabular}{|c|c|c|c|c|c|}
\hline & 1 & 2 & 3 & 4 & 5 \\
\hline Estimation Method & 2SLS & 2SLS & 2SLS & 2SLS & 2SLS \\
\hline Dependent Variable & Litigation Dummy & Litigation Dummy & Litigation Dummy & Litigation Dummy & Litigation Dummy \\
\hline NewOwner & $\begin{array}{c}0.338^{* * *} \\
(0.120)\end{array}$ & $\begin{array}{l}-0.429 * \\
(0.236)\end{array}$ & $\begin{array}{c}-0.278^{* * *} \\
(0.081)\end{array}$ & $\begin{array}{l}-0.383 \\
(0.262)\end{array}$ & $\begin{array}{c}-0.238^{* * *} \\
(0.081)\end{array}$ \\
\hline NewOwner x LargeBuyer & & & & & $\begin{array}{l}-0.365^{*} \\
(0.196)\end{array}$ \\
\hline NewOwner $x$ TechFit & & & & & $\begin{array}{l}0.461^{* * *} \\
(0.137)\end{array}$ \\
\hline Sample & $\begin{array}{c}\text { Trades to small buyers and } \\
\text { high patent fit }\end{array}$ & $\begin{array}{l}\text { Trades to large buyers } \\
\text { and low patent fit }\end{array}$ & $\begin{array}{c}\text { Trades to small buyers } \\
\text { and low patent fit }\end{array}$ & $\begin{array}{c}\text { Trades to large buyers } \\
\text { and high patent fit }\end{array}$ & $\begin{array}{l}\text { All traded and } \\
\text { Litigated Patents }\end{array}$ \\
\hline Observations & 1585 & 507 & 4361 & 357 & 6810 \\
\hline Patents & 116 & 47 & 382 & 24 & 569 \\
\hline
\end{tabular}

NOTES: All regressions include age dummies, period dummies and patent fixed effects. Standard errors clustered at patent level are reported in parentheses. Statistical significance:

* 10 percent, $* * 5$ percent, *** 1 percent. Litigation Dummy $=1$ if the patent is involved in at least one case at that age; NewOwner $=1$ when the patent changes ownership for the first time and remains equal to one for the remaining life of the patent. Time Period Dummies: before 1986, 1986-1990, 1991-1995, after 1995. LargeBuyer=1 if acquirer obtained more than 8 patents in the 20 years before trade. TechFit=1 if acquired patent belongs to technology sub-category in which buyer has more patents. NewOwner and its interactions are instrumented by the Probit estimates of the probability of not being owned by the original inventor. 
TABLE 6: The Roles of Buyer Portofolio Size and Patent Fit - Robustness

\begin{tabular}{|c|c|c|c|c|}
\hline & 1 & 2 & 3 & 4 \\
\hline Estimation Method & 2SLS & 2SLS & 2SLS & 2SLS \\
\hline \multirow[t]{2}{*}{ Dependent Variable } & Litigation Dummy & Litigation Dummy & Litigation Dummy & Litigation Dummy \\
\hline & $\begin{array}{c}\text { LargeBuyer }=1 \text { if } \\
\text { more than } 12 \text { patents }\end{array}$ & $\begin{array}{l}\text { TechFit=0 if trade } \\
\text { among individuals }\end{array}$ & $\begin{array}{l}\text { TechFit constructed with } \\
\text { narrow technology classes }\end{array}$ & $\begin{array}{c}\text { TechFit defined using } \\
\text { patent citations }\end{array}$ \\
\hline \multirow[t]{2}{*}{ NewOwner } & $-0.221 * * *$ & $-0.130 * *$ & $-0.190 * *$ & $-0.227 * * *$ \\
\hline & $(0.08)$ & $(0.06)$ & $(0.08)$ & $(0.08)$ \\
\hline \multirow[t]{2}{*}{ NewOwner x LargeBuyer } & $-0.394 *$ & $-0.338 *$ & $-0.343^{*}$ & $-0.401 * *$ \\
\hline & $(0.22)$ & $(0.19)$ & $(0.19)$ & $(0.20)$ \\
\hline \multirow[t]{2}{*}{ NewOwner x TechFit } & $0.450 * * *$ & $0.133^{* * *}$ & $0.383^{* * *}$ & $0.484^{* * *}$ \\
\hline & $(0.13)$ & $(0.04)$ & $(0.14)$ & $(0.13)$ \\
\hline \multirow{2}{*}{ Sample } & Traded and Litigated & Traded and Litigated & Traded and Litigated & Traded and Litigated \\
\hline & Patents & Patents & Patents & Patents \\
\hline Observations & 6810 & 6810 & 6810 & 6810 \\
\hline Patents & 569 & 569 & 569 & 569 \\
\hline
\end{tabular}

NOTES: Standard errors clustered at patent level are reported in parentheses. All regressions include age dummies, period dummies and patent fixed effects. Statistical significance: ${ }^{*} 10$ percent, ${ }^{* *} 5$ percent, ${ }^{* * *} 1$ percent. Litigation Dummy $=1$ if the patent is involved in at least one case at that age; NewOwner $=1$ when the patent changes ownership for the first time and remains equal to one for the remaining life of the patent. Time Period Dummies: before 1986, 1986-1990, 1991-1995, after 1995. In columns 2 to 4 Large Buyer=1 if acquirer obtained more than 8 patents in the 20 years before trade. In columns 1 and 2 TechFit=1 if acquired patent belongs to technology sub-category in which buyer has more patents. In column 3 TechFit constructed using USPTO patent nclasses. In column 4 TechFit=1 if either the acquired patent cites one of the patents of the buyer or if the patents of the buyer cite the acquired patent. NewOwner and its interactions are instrumented by the Probit estimates of the probability of not being owned by the original inventor. 
TABLE 7: Effect of Capital Gain Taxes on Frequency of Patent Trade and Litigation

\begin{tabular}{cccc}
\hline Scenario & $\begin{array}{c}\text { Capital Gains Taxes } \\
\text { (in percentage) }\end{array}$ & $\begin{array}{c}\text { Traded Patents per } \\
\mathbf{1 0 0 0} \text { patents }\end{array}$ & $\begin{array}{c}\text { Predicted Suits per } \\
\mathbf{1 0 0 0} \text { patents }\end{array}$ \\
\hline \hline Baseline & 29.2 & 56.9 & 35.8 \\
Low Tax & 20.0 & 92.5 & 23.1 \\
High Tax & 40.0 & 30.9 & 45.5 \\
$\begin{array}{c}\text { Capital Gains Tax } \\
=\text { Income Tax }\end{array}$ & 42.6 & 26.4 & 47.1 \\
$\begin{array}{c}\text { Capital Gains Tax } \\
=\text { Income Tax }\end{array}$ & 29.2 & 35.1 & 44.1 \\
\hline
\end{tabular}


FIGURE 1. Trade and Likelihood of Litigation

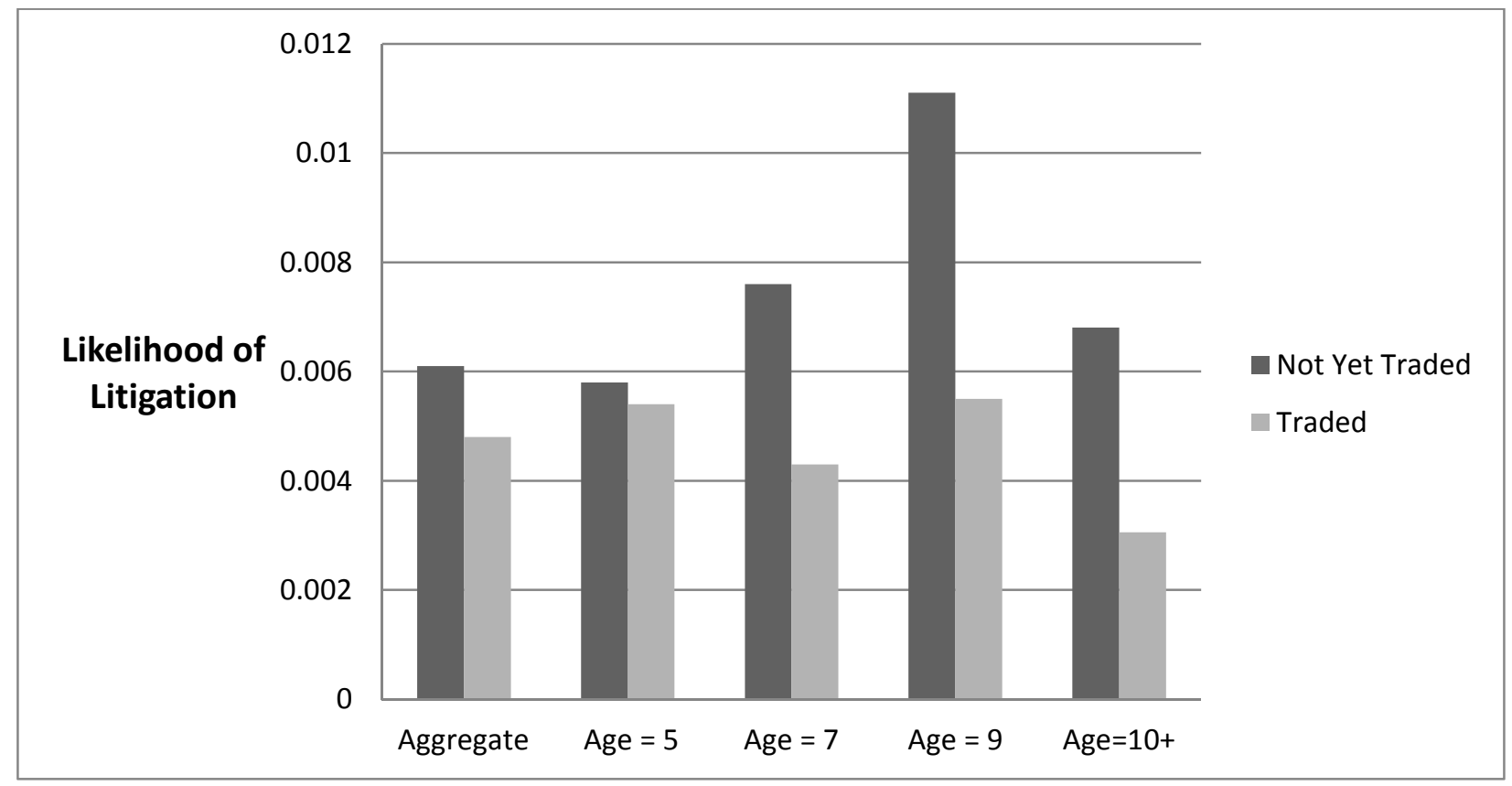


FIGURE 2. Marginal Treatment Effect- Entire Sample

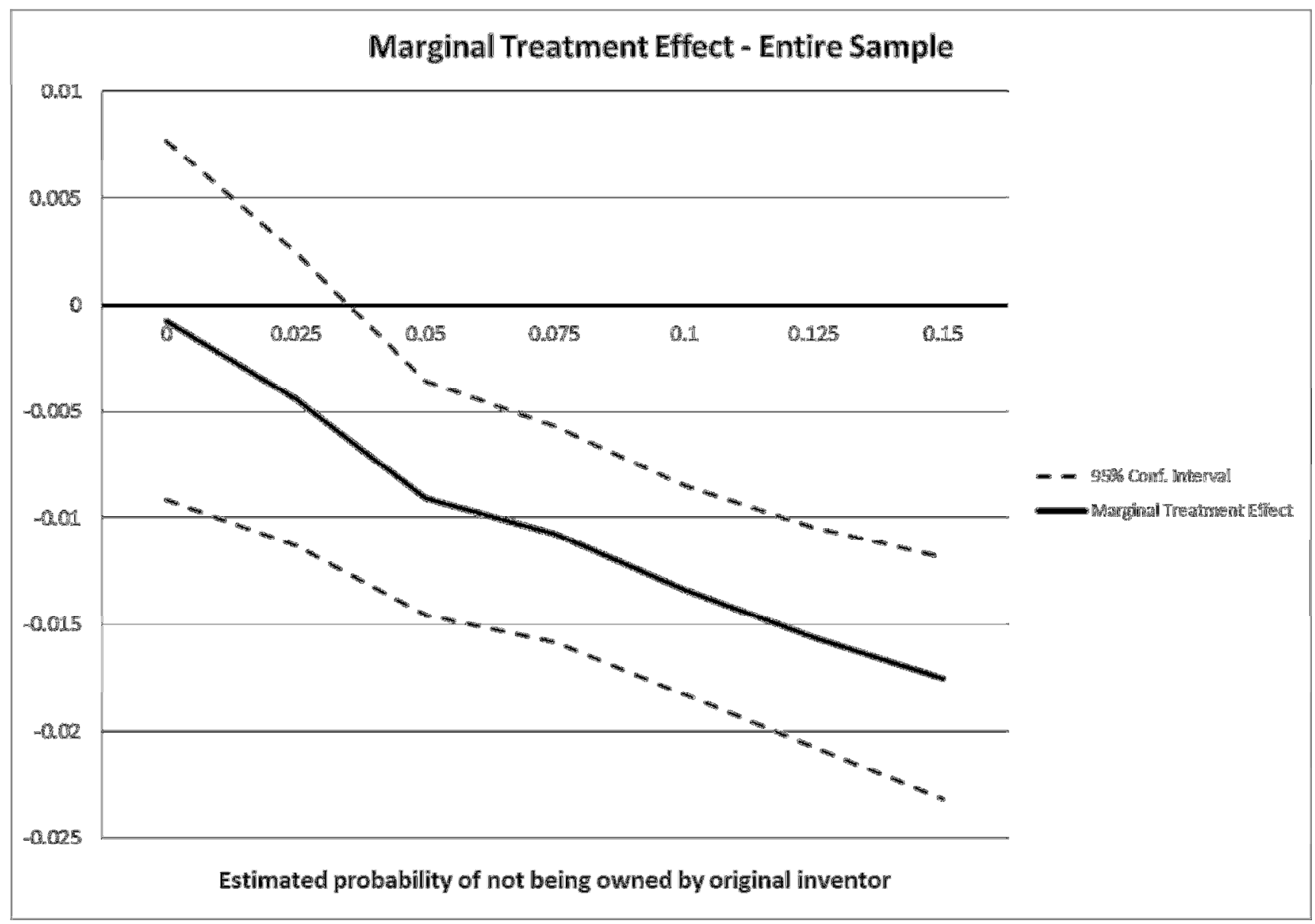


FIGURE 3. Marginal Treatment Effect - Litigated and Traded Patents

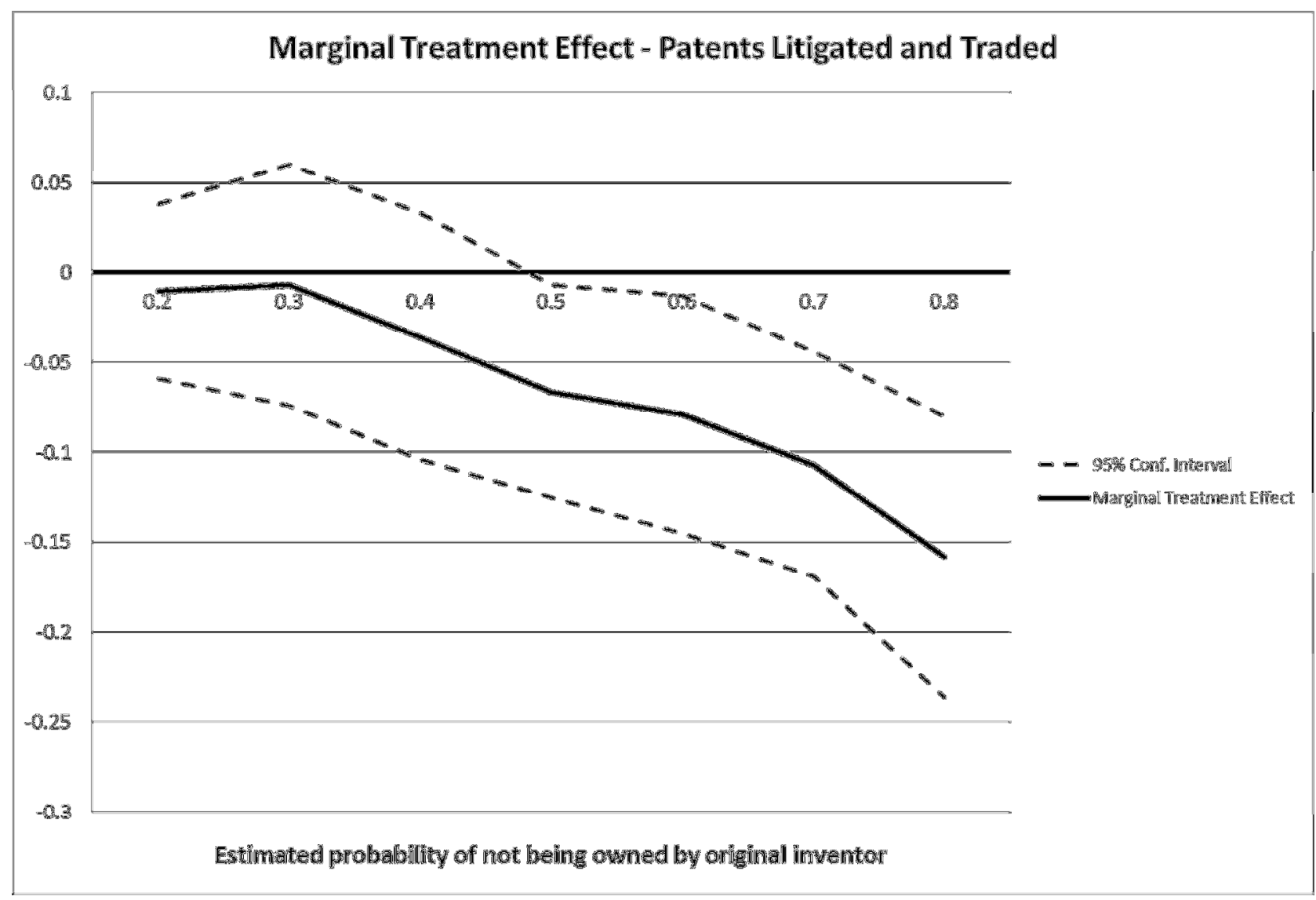




\section{CENTRE FOR ECONOMIC PERFORMANCE \\ Recent Discussion Papers}

1071

Daniel Hale

John Coleman

Richard Layard

1070 David Marsden

1069 Ross Levine

Alexey Levkov

Yona Rubinstein

1068 Klaus Adam

Albert Marcet

1067 Yanhui $\mathrm{Wu}$

1066 Yanhui $\mathrm{Wu}$

1065 Nicholas Bloom

Helena Schweiger

John Van Reenen

1064 Klaus Adam

Pei Kuang

Albert Marcet

1063 Stephen Hansen

Michael McMahon

1062 Paul Dolan

Daniel Fujiwara

Robert Metcalfe

1061 Marek Jarocinski

Albert Marcet

1060 Christos Genakos

Kai Uwe Kühn

John Van Reenen

1059 Klaus Adam

Albert Marcet

1058 Michael W. L. Elsby Jennifer C. Smith Jonathan Wadsworth

1057 Fabrice Defever
A Model for the Delivery of Evidence-Based PSHE (Personal Wellbeing) in Secondary

Schools

Individual Voice in Employment

Relationships: A Comparison Under Different

Forms of Workplace Representation

Racial Discrimination and Competition

Internal Rationality, Imperfect Market

Knowledge and Asset Prices

A Simple Theory of Managerial Talent, Pay

Contracts and Wage Distribution

Managerial Incentives and Compensation in a Global Market

The Land that Lean Manufacturing Forgot?

Management Practices in Transition

Countries

House Price Booms and the Current Account

How Experts Decide: Identifying Preferences versus Signals from Policy Decisions

A Step towards Valuing Utility the Marginal and Cardinal Way

Autoregressions in Small Samples, Priors about Observables and Initial Conditions

Leveraging Monopoly Power by Degrading Interoperability: Theory and Evidence from Computer Markets

Booms and Busts in Asset Prices

The Role of Worker Flows in the Dynamics and Distribution of UK Unemployment

Incomplete Contracts and the Impact of Globalization on Consumer Welfare 
1056 Fadi Hassan

1055 Albert Marcet

Ramon Marimon

1054 Olivier Cadot

Leonardo Iacovone

Denisse Pierola

Ferdinand Rauch

1053 Björn Eriksson

Tobias Karlsson

Tim Leunig

Maria Stanfors

1052 Hartmut Lehmann

Jonathan Wadsworth

1051 Jörn-Steffen Pischke

1050 Tim Leunig

Joachim Voth

1049 Francesca Cornaglia

Andrew Leigh

1048 Gianluca Benigno

Hande Küçük-Tuger

1047 Guy Mayraz

1046 Petri Böckerman

Alex Bryson

Pekka Ilmakunnas

1045 Christos Genakos

Tommaso Valletti

1044 Giordano Mion

Luca David Opromolla

1043 Javier Ortega

Gregory Verdugo
The Penn-Belassa-Samuelson Effect in

Developing Countries: Price and Income Revisited

Recursive Contracts

Success and Failure of African Exporters

Gender, Productivity and the Nature of Work and Pay: Evidence from the Late NineteenthCentury Tobacco Industry

The Impact of Chernobyl on Health and Labour Market Performance

Money and Happiness: Evidence from the Industry Wage Structure

Spinning Welfare: the Gains from Process Innovation in Cotton and Car Production

Crime and Mental Wellbeing

Portfolio Allocation and International Risk Sharing

Priors and Desires: A Model of PayoffDependent Beliefs

Does High Involement Management Lead to Higher Pay?

Seesaw in the Air: Interconnection

Regulation and the Structure of Mobile

Tariffs

Managers' Mobility, Trade Status and Wages

Immigration and the Occupational Choice of Natives: A Factor Proportions Approach

The Centre for Economic Performance Publications Unit

Tel 02079557673 Fax 02079557595

Email info@cep.lse.ac.uk Web site http://cep.lse.ac.uk 